\title{
Prevalence of Hip and Knee Arthroplasty
}

Florian Rothbauer, Ute Zerwes, Hans-Holger Bleß, Miriam Kip

2.1 Database -16

2.2 Utilization of Primary Arthroplasty - 19

2.3 Utilization of Revision Total Arthroplasty and Revision Surgery -21

2.4 Regional Distribution -23

2.5 Case Number Developments - 26

2.5.1 Primary Arthroplasty - 26

2.5.2 Revision Total Arthroplasty and Revision Surgery - 29

2.6 International Comparison - 31

References - 39 


\section{Summary}

The annual rate of primary hip and knee arthroplasty has not increased since 2007. In the 70 years plus age group, the rate of primary hip arthroplasty was $1.1 \%$ (in both 2007 and 2014) and the rate of primary knee arthroplasty was $0.7 \%$ in 2007 and $0.6 \%$ in 2014. In 2014, the prevalence of surgery in relation to the entire population was $0.26 \%$ for the hip and $0.19 \%$ for the knee. Approximately 219,000 primary hip replacements and 149,000 primary knee replacements were documented in Germany in 2014. The most common procedure performed on a joint was total replacement. Approximately $40 \%$ of all primary hip or knee replacements are performed in patients in the 70 to 79 year age group; women are more frequently affected than men (ratio 2:1). In 2014, the absolute number of revisions (including revisions without replacements) amounted to approximately 30,000 for the hip and 20,000 for the knee. The number of revisions performed in any given year is not necessarily directly related to the number of primary replacements performed in the same year. Instead, the number of revisions should be considered in relation to the cumulative number of primary replacements performed over the past years and decades. As with primary arthroplasty, approximately $40 \%$ of the revisions are performed on patients in the 70 to 79 years age group. However, the difference between men and women is less pronounced.

Between 2007 and 2014, the rate of hip and knee revision replacements (including revision without replacements) also remained stable. In 2014, in the 70 years plus age group, the rate of revision replacements (including revision without replacements) was $0.19 \%$ for the hip and $0.10 \%$ for the knee. The annual utilization rate of primary hip and knee arthroplasty varies internationally. Regional differences also exist within Germany itself, as evaluations conducted by the statutory health insurances for the period from 2005 to 2011 have shown. A comparatively low utilization rate was associated in particular with low incidences of osteoarthritis, low social status, a high number of regional specialist physicians (orthopedists) and patients living in urban areas.

Hip and knee arthroplasty constitute effective treatments for patients with substantial (or impending) permanently restricted joint function due to joint destruction or pain which can no longer be treated otherwise. They are also used to treat fractures near the joint. The different types of arthroplasty procedures aim to restore good joint function, weight-bearing capacity and quality of life. The prevalence (utilization) of arthroplasty is an important aspect for planning ambulatory and inpatient care, as well as for estimating demands and subsequent demands such as rehabilitation measures and questions with regard to resource allocation. The following chapter presents the utilization hip and knee arthroplasty services in Germany and differentiates these according to age and gender, type of procedure and fixation technique. The presentation distinguishes between primary and revision arthroplasty. Furthermore, this chapter investigates regional differences in distribution of these medical care services and in temporal developments with regard to their utilization in Germany and compares these internationally.

\subsection{Database}

The German procedure classification »Operationen- und Prozedurenschlüssel (OPS) « enables detailed observations of the annual inpatient primary and revision hip and knee replacements performed in Germany. In the German healthcare system, the OPS is primarily used for administrative purposes to identify the services rendered to inpatients.

Bone and joint replacements are classified in Section 5-82 of the OPS (• Tab. 2.1). The coding system allows for reliable distinctions to be made between primary arthroplasty, revision, revision total arthroplasty and the removal of hip joints (5$820 / 5-821)$ and knee joints (5-822/5-823). In addition, age and sex of patients are specified. OPS 5-820 and 5-822 document primary endoprosthetic care (primary arthroplasty) for hip and knee joints respectively. OPS 5-821 and 5-823 and further differentiated sub-codes refer to revision surgery, i.e. revision total arthroplasty and revisions (follow-up surgery and re-revisions) on joints that have already undergone previous endoprosthetic surgery. 
OPS

description

Hip: Primary arthroplasty

\begin{tabular}{|l|l|l|l|}
\hline $5-820.0$ & Total arthroplasty & $5-820.2$ & Total arthroplasty, custom-made prosthesis \\
\hline $5-820.3$ & Femoral head prosthesis & $5-820.4$ & Dual head prosthesis \\
\hline $5-820.5$ & Acetabular support cup & $5-820.7$ & Acetabular liner locking cup \\
\hline $5-820.8$ & Surface replacement & $5-820.9$ & Short-stem femoral head prosthesis \\
\hline $5-820 . x$ & Other & $5-820 . y$ & Unspecified \\
\hline
\end{tabular}

Hip: Revision total arthroplasty and revision

\begin{tabular}{|c|c|c|c|}
\hline $5-821.0$ & Revision (without replacement) & $5-821.1$ & Femoral head prosthesis replacement \\
\hline $5-821.2$ & Acetabular cup replacement & $5-821.3$ & Revision cemented total arthroplasty \\
\hline $5-821.4$ & Revision uncemented total arthroplasty & $5-821.5$ & $\begin{array}{l}\text { Revision total arthroplasty, hybrid endo- } \\
\text { prosthesis }\end{array}$ \\
\hline $5-821.6$ & $\begin{array}{l}\text { Revision total arthroplasty, custom-made } \\
\text { prosthesis }\end{array}$ & $5-821.7$ & Total endoprosthesis removal \\
\hline $5-821.8$ & Femoral head prosthesis removal & $5-821.9$ & Dual head prosthesis removal \\
\hline 5-821.a & Femoral head cap removal & 5-821.b & Acetabular cup removal \\
\hline 5-821.c & Acetabular support cup removal & 5-821.d & Acetabular liner locking cup removal \\
\hline 5-821.e & $\begin{array}{l}\text { Total endoprosthesis removal, custom- } \\
\text { made prosthesis }\end{array}$ & 5-821.f & Dual head prosthesis replacement \\
\hline $5-821.9$ & Surface prosthesis replacement & 5-821.h & Surface prosthesis removal \\
\hline 5-821.j & $\begin{array}{l}\text { Femoral neck preserving femoral head } \\
\text { prosthesis (short-stem femoral head } \\
\text { prosthesis) replacement }\end{array}$ & 5-821.k & $\begin{array}{l}\text { Femoral neck preserving femoral head } \\
\text { prosthesis (short-stem femoral head } \\
\text { prosthesis) removal }\end{array}$ \\
\hline $5-821 . x$ & Other & 5-821.y & Unspecified \\
\hline
\end{tabular}

\section{Knee: Primary arthroplasty}

5-822.0 Unicondylar sledge prosthesis

5-822.2 Bicondylar surface prosthesis, unconstrained, with patella replacement

$5-822.4$

5-822.7

$5-822.9$

$5-822 . b$

5-822.d

\section{Bicondylar surface prosthesis, partially} constrained, without patella replacement

Hinged endoprosthesis, with patella replacement

Custom-made prosthesis

Endoprosthesis with enhanced flexion, with patella replacement

Bicompartmental replacement, without patella replacement
5-822.1 Bicondylar surface prosthesis, unconstrained, without patella replacement

5-822.3 Bicondylar surface replacement prosthesis, partially constrained, with patella replacement

5-822.6 Hinged endoprosthesis, without patella replacement

\begin{tabular}{l|l}
$5-822.8$ & Patella replacement
\end{tabular}

5-822.a Endoprosthesis with enhanced flexion, without patella replacement

\begin{tabular}{l|l}
$5-822 . c$ & Interpositional non-anchored implant
\end{tabular}

5-822.e

Bicompartmental replacement, with patella replacement 
Tab. 2.1 OPS classification

\begin{tabular}{|c|c|c|c|}
\hline OPS & description & OPS & description \\
\hline $5-822 . f$ & $\begin{array}{l}\text { Implantation of an endoprosthetic joint } \\
\text { without movement function 5-822.x }\end{array}$ & $5-822 . x$ & Other \\
\hline 5-822.y & Unspecified & & \\
\hline \multicolumn{4}{|c|}{ Knee: Revision and replacement operation } \\
\hline $5-823.0$ & Revision (without replacement) & $5-832.1$ & Unicondylar sledge prosthesis replacement \\
\hline $5-823.2$ & Bicondylar sledge prosthesis replacement & $5-823.3$ & Hinged endoprosthesis replacement \\
\hline $5-823.4$ & Custom-made prosthesis replacement & $5-823.5$ & Patella prosthesis replacement \\
\hline $5-823.6$ & Unicondylar sledge prosthesis removal & $5-823.7$ & Bicondylar surface prosthesis removal \\
\hline $5-823.8$ & Hinged endoprosthesis removal & $5-823.9$ & Patella prosthesis replacement \\
\hline 5-823.a & Custom-made prosthesis removal & $5-823 . b$ & $\begin{array}{l}\text { Replacement of an endoprosthesis with } \\
\text { enhanced flexion }\end{array}$ \\
\hline 5-823.c & $\begin{array}{l}\text { Replacement of an interpositional non- } \\
\text { anchored implant }\end{array}$ & 5-823.d & $\begin{array}{l}\text { Removal of an endoprosthesis with } \\
\text { nhanced flexion }\end{array}$ \\
\hline 5-823.e & $\begin{array}{l}\text { Removal of an interpositional non-an- } \\
\text { chored implant }\end{array}$ & 5-823.f & Bicompartmental prosthesis replacement \\
\hline $5-823.9$ & Bicompartmental prosthesis removal & 5-823.h & $\begin{array}{l}\text { Replacement of endoprosthetic joint } \\
\text { without movement function }\end{array}$ \\
\hline 5-823.j & $\begin{array}{l}\text { Removal of an endoprosthetic joint with- } \\
\text { out movement function }\end{array}$ & 5-823.x & Other \\
\hline 5-823.y & Unspecified & & \\
\hline
\end{tabular}

The German Federal Statistical Office (Statistisches Bundesamt) makes OPS data publicly available as is stipulated by $\$ 21$ of the German Hospital Remuneration Act. Only case-based and not patient-based data can be accessed. Consequently, the number of cases does not (necessarily) correspond to the number of patients. Two-stage surgery is documented as two separate cases and subsequently individual patients may be counted multiple times.

The Federal Statistical Office dataset does not permit statistical evaluations of the surgical access, endoprosthetic material or of whether the surgery was planned or had to be performed as an emergency. Determining the durability of the endoprostheses (service life) is also not possible as no connection can be made between the actual implantation and prosthesis removal for individual pa- tients. The Federal Statistical Office dataset also does not portray connections to underlying indications (osteoarthritis, fractures and other causes). Although hospitals report connections between diagnoses and procedures to the respective health insurances and the German Institute for Hospital Reimbursement (InEK), combining this data publicly is not possible. Moreover, further clinical parameters required for describing indications such as pain, joint function or quality of life are not depicted. Connections with indications and procedures, for example, will be made possible in the future through the German joint replacement registry "Endoprothesenregister Deutschland (EPRD)« ( $\downarrow$ Chapter 4 ). As the risk of having to undergo joint replacement is not uniformly spread across all population and age groups, reliable statements about 


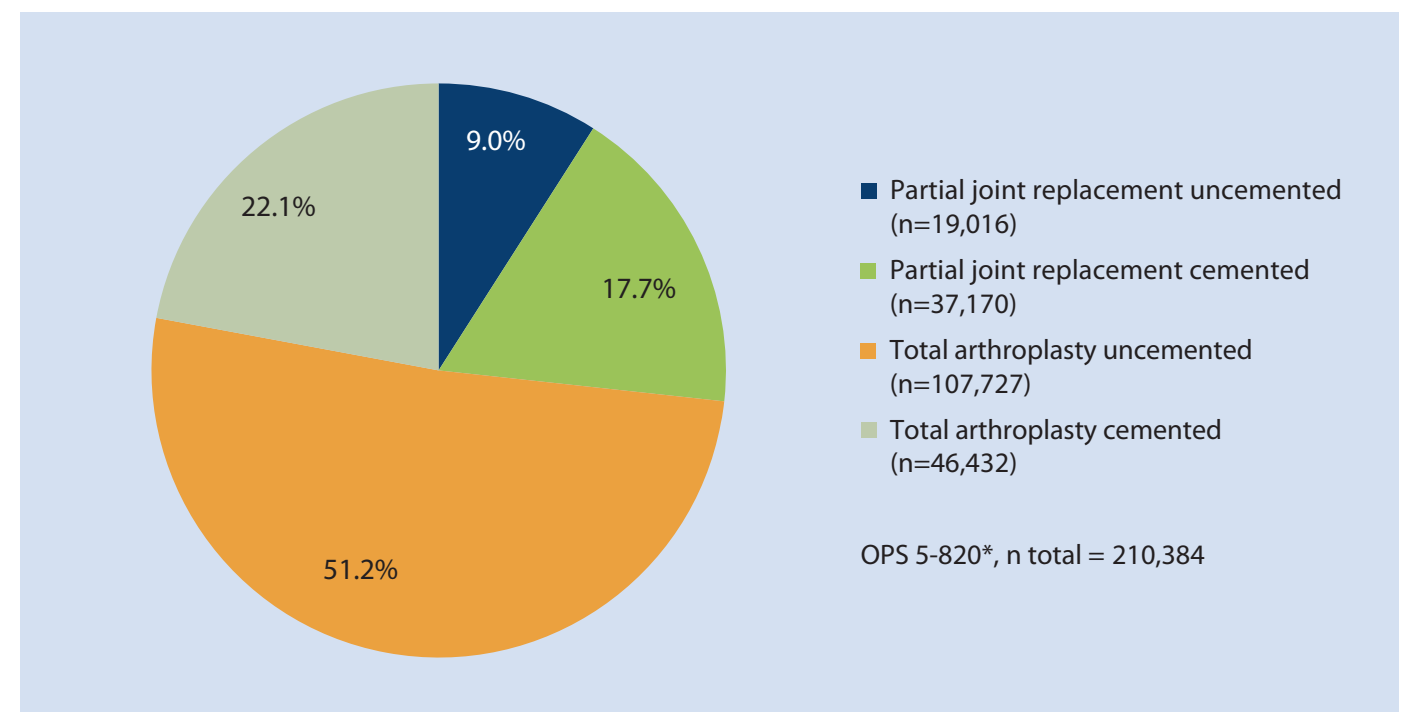

- Fig. 2.1 Distribution of hip joint arthroplasty utilization $(n=210,384)($ OPS 5-820.*) by total and partial replacement and fixation technique (2013). (IGES - Federal Statistical Office 2014)

the differences in prevalence (for example, in regional and international comparisons) can only be made after adjusting or standardising the respective databases for influencing characteristics such as age or sex. Regional evaluations of health insurance data (for example by Schäfer et al. 2013; Lüring et al. 2013) usually report prevalence rates that are standardized to population structures. Furthermore, consistent survey methods should be employed to ensure good reliability for making comparisons. Presentations of patient-related OECD data that internationally compare prevalences of endoprosthetic hip and knee surgery usually do not take these aspects into sufficient consideration ( $\triangleright$ Chapter 6$)$.

\subsection{Utilization of Primary Arthroplasty}

According to data from the Federal Statistical Office, a total of 219,325 primary hip arthroplasties were performed in 2014 and 210,384 in 2013 (absolute numbers). Out of the 210,384 primary hip arthroplasties performed in 2013, 154,159 (73.3\%) were total arthroplasties (THA) and 56,225 (26.7 \%) were partial arthroplasties. $60.2 \%$ (126,743 cases) of all hip endoprostheses were implanted without ce- ment (Federal Statistical Office 2014) (• Fig. 2.1). In 2014 , the rate of surgery in the general population (as determined on 31 December 2014) was $0.26 \%$ (own calculation, Federal Statistical Office 2014, Federal Statistical Office 2015).

The absolute number of primary knee arthroplasties was 149,126 in 2014 and 143,024 in 2013. $84 \%$ of the 143,024 primary knee arthroplasties performed in 2013 were bicondylar replacements (- Fig. 2.2). The rate of knee replacement surgery in the total population (as determined on 31 December 2014) was $0.19 \%$ in 2014 (own calculation, Federal Statistical Office 2014, Federal Statistical Office 2015). In contrast to primary hip arthroplasty, the majority of primary knee arthroplasties (79.6\%) were fixated with cement. Entirely uncemented fixation was documented in $10.5 \%$ of all operations and hybrid/partially cemented fixation was documented in $9.6 \%$ of the primary replacements (Federal Statistical Office 2014).

In the age group of over 60 -year-olds, well over $65 \%$ of primary hip or knee replacements were performed in women (Federal Statistical Office 2014). A higher proportion of female hip and knee arthroplasty patients has also been well documented elsewhere (Braun 2013; Lüring et al. 2013). The higher percentage of female patients is due to the higher 


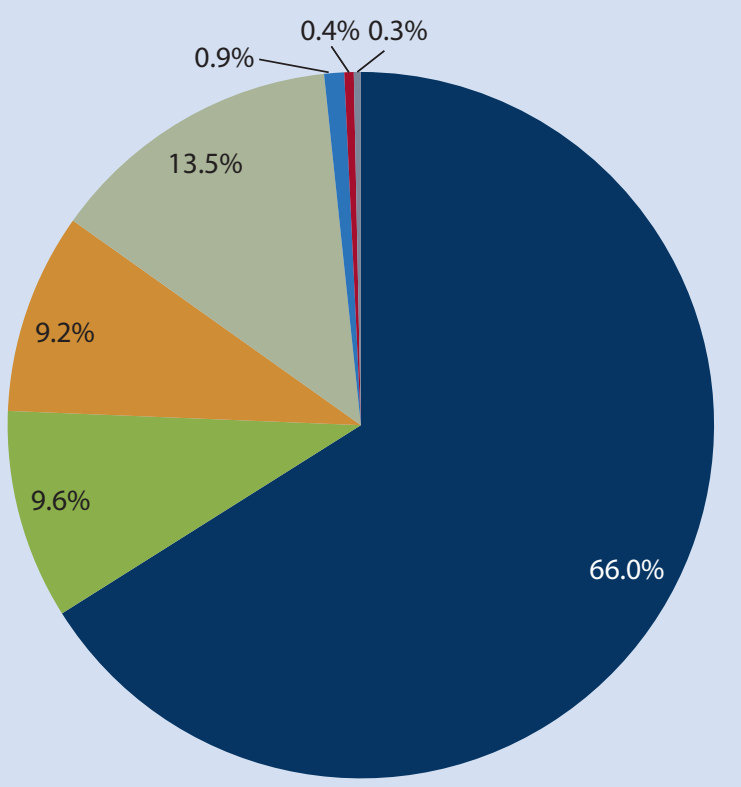

TKA cemented $(n=94,466)$

- TKA uncemented $(n=13,723)$

- TKA hybrid $(n=13,141)$

nartial replacement cemented $(n=19,318)$

- Partial replacement uncemented $(n=1,304)$

- Partial replacement hybrid $(n=617)$

Other (incl. non-anchored) $(n=455)$

- Fig. 2.2 Distribution of primary knee arthroplasty utilization (absolute number, $n=143,024)($ OPS 5-822.*) by total and partial replacement and fixation technique (2013). (IGES - Federal Statistical Office 2014)

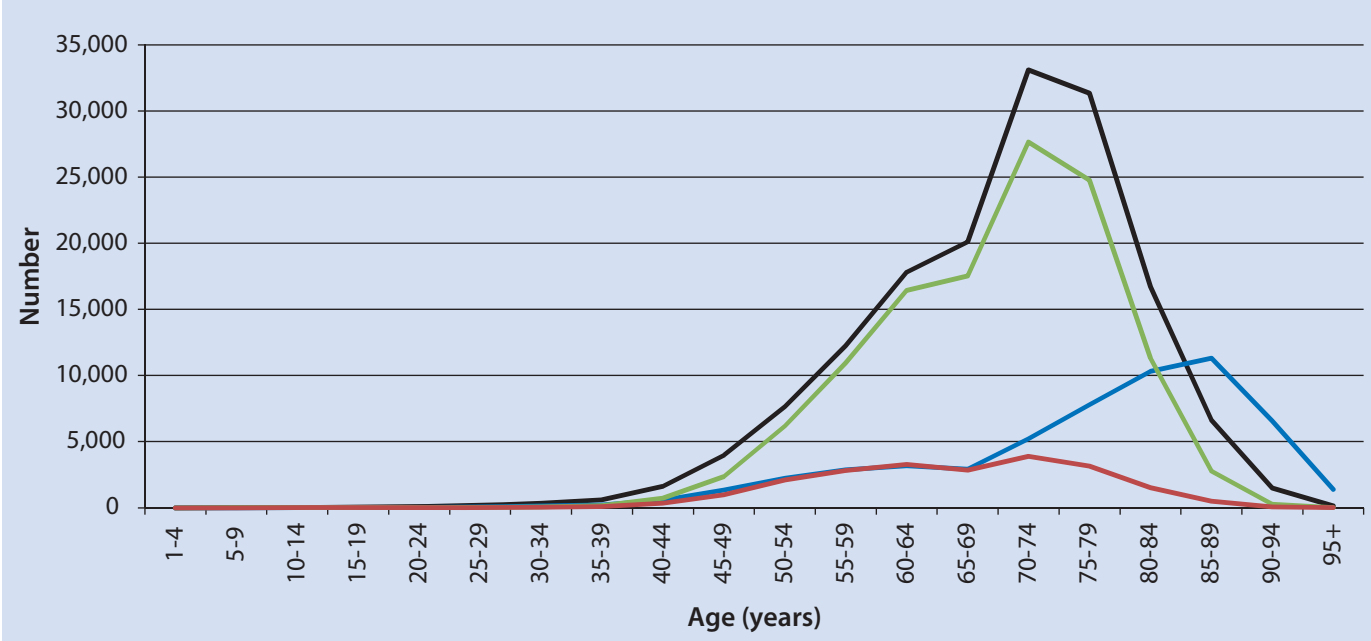

— Hip: Total arthroplasty _ - Hip: Partial replacement _ Knee: Total arthroplasty _ Knee: Partial replacement

- Fig. 2.3 Utilization (absolute number) of primary hip and knee arthroplasty by total and partial replacement and age group (2013). (IGES - Federal Statistical Office 2014) 
prevalence of osteoarthritis in women (most common indication for hip or knee arthroplasty) in addition to a significantly longer life expectancy for women (Rabenberg 2013).

Primary surgery is clearly associated with patient age: Approximately $40 \%$ of all primary hip or knee replacements documented in Germany are performed in the 70 to 79 year age group (• Fig. 2.3). In 2013 , the average age at the time of the primary total hip or knee arthroplasty was 69.7 and 69.2 years respectively. Patients who underwent partial knee replacement were slightly younger on average (mean age 65.8 years). In contrast, the highest number of patients who underwent partial hip replacement was observed in the 85 to 89 year age group. This age group has more documented cases of primary partial hip replacements than of total hip replacements. This is primarily due to the high prevalence of femoral neck fractures which occur particularly often in this age group and are predominantly treated with partial replacements (Section 1.2.1 and Section 1.2.2)

(• Fig. 2.3) (Federal Statistical Office 2014).

There is also a link between patient age and the employed fixation technique: The proportion of cemented total hip arthroplasties (THA) increases with age in comparison to uncemented THA (Federal Statistical Office 2014).

\subsection{Utilization of Revision Total Arthroplasty and Revision Surgery}

According to the Federal Statistical Office, a total of 35,133 revision hip arthroplasties were performed in 2014 and a total of 31,067 revision hip arthroplasties and 21,678 revision knee arthroplasties were performed in 2013 (including revisions without replacements) (absolute numbers). In 2014, this corresponded to a prevalence of surgery of $0.04 \%$ (hip) and $0.06 \%$ (knee) respectively in the general population (as determined on 31 December 2014) (own calculation, Federal Statistical Office 2014, Federal Statistical Office 2015). 3,784 cases and 3,213 cases were revisions without component replacements on the hip and the knee respectively. Accordingly, revisions without replacements accounted for approximately $12 \%$ and $16 \%$ of all documented hip and
Tab. 2.2 Utilization (absolute number) of revision total replacements and revisions on the hip and knee (2013)

\begin{tabular}{|c|c|c|}
\hline \multirow{2}{*}{$\begin{array}{l}\text { Description } \\
\text { Hip joint }\end{array}$} & \multicolumn{2}{|c|}{ Prevalence } \\
\hline & n & $\%$ \\
\hline \multicolumn{3}{|l|}{ Total arthroplasty } \\
\hline $\begin{array}{l}\text { Revision total arthroplasty } \\
\text { (uncemented) }\end{array}$ & 4,537 & 14.6 \\
\hline $\begin{array}{l}\text { Revision total arthroplasty } \\
\text { (cemented) }\end{array}$ & 2,325 & 7.5 \\
\hline $\begin{array}{l}\text { Revision total arthroplasty (partially } \\
\text { cemented) }\end{array}$ & 871 & 2.8 \\
\hline $\begin{array}{l}\text { Custom-made prosthesis replace- } \\
\text { ment }\end{array}$ & 837 & 2.7 \\
\hline \multicolumn{3}{|l|}{ Partial replacement } \\
\hline $\begin{array}{l}\text { Acetabular cup component replace- } \\
\text { ment }\end{array}$ & 12,473 & 40.1 \\
\hline Femoral head prosthesis replacement & 4,859 & 15.6 \\
\hline Dual head prosthesis replacement & 941 & 3.0 \\
\hline Surface prosthesis replacement & 221 & 0.7 \\
\hline $\begin{array}{l}\text { Femoral neck preserving femoral } \\
\text { head prosthesis replacement }\end{array}$ & 219 & 0.7 \\
\hline Revision (without replacement) & 3,784 & 12.2 \\
\hline $\begin{array}{l}\text { Revision total arthroplasty and } \\
\text { revisions, total }\end{array}$ & 31,067 & 100 \\
\hline Knee & n & $\%$ \\
\hline Bicondylar surface prosthesis & 11,290 & 55.4 \\
\hline $\begin{array}{l}\text { Unicondylar sledge prosthesis } \\
\text { replacement }\end{array}$ & 2,317 & 11.4 \\
\hline Hinged endoprosthesis replacement & 1,222 & 6.0 \\
\hline $\begin{array}{l}\text { Endoprosthesis with enhanced } \\
\text { flexion replacement }\end{array}$ & 699 & 3.4 \\
\hline Custom-made prosthesis replacement & 533 & 2.6 \\
\hline $\begin{array}{l}\text { Bicompartmental prosthesis } \\
\text { replacement }\end{array}$ & 459 & 2.3 \\
\hline Patella replacement & 439 & 2.2 \\
\hline Other & 212 & 1.0 \\
\hline Revision (without replacement) & 3,213 & 15.8 \\
\hline Total & 20,384 & 100 \\
\hline
\end{tabular}

Source: IGES - Federal Statistical Office (2014) 


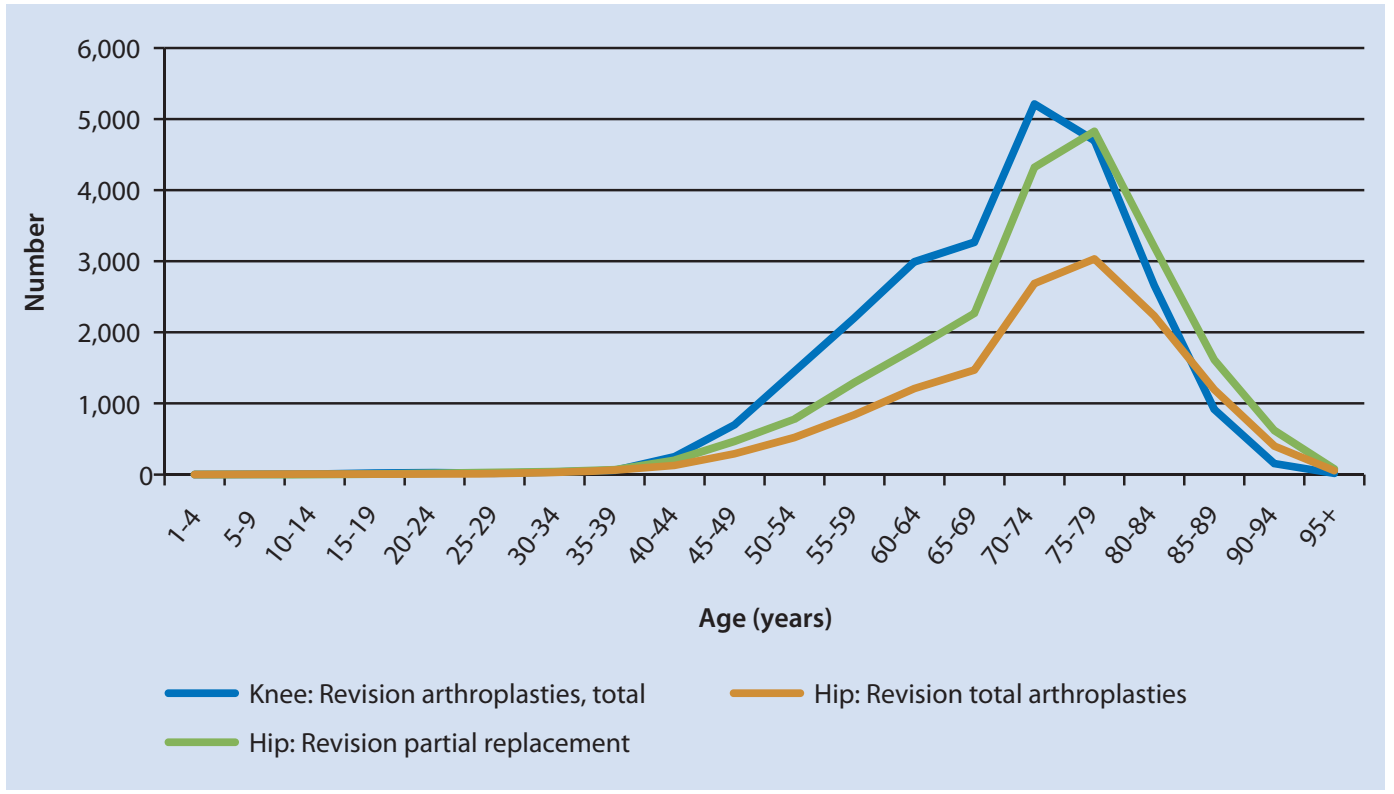

- Fig. 2.4 Utilization of revision arthroplasty (absolute number) including revisions without replacements by type and age group (2013). (Source: IGES - Federal Statistical Office 2014)

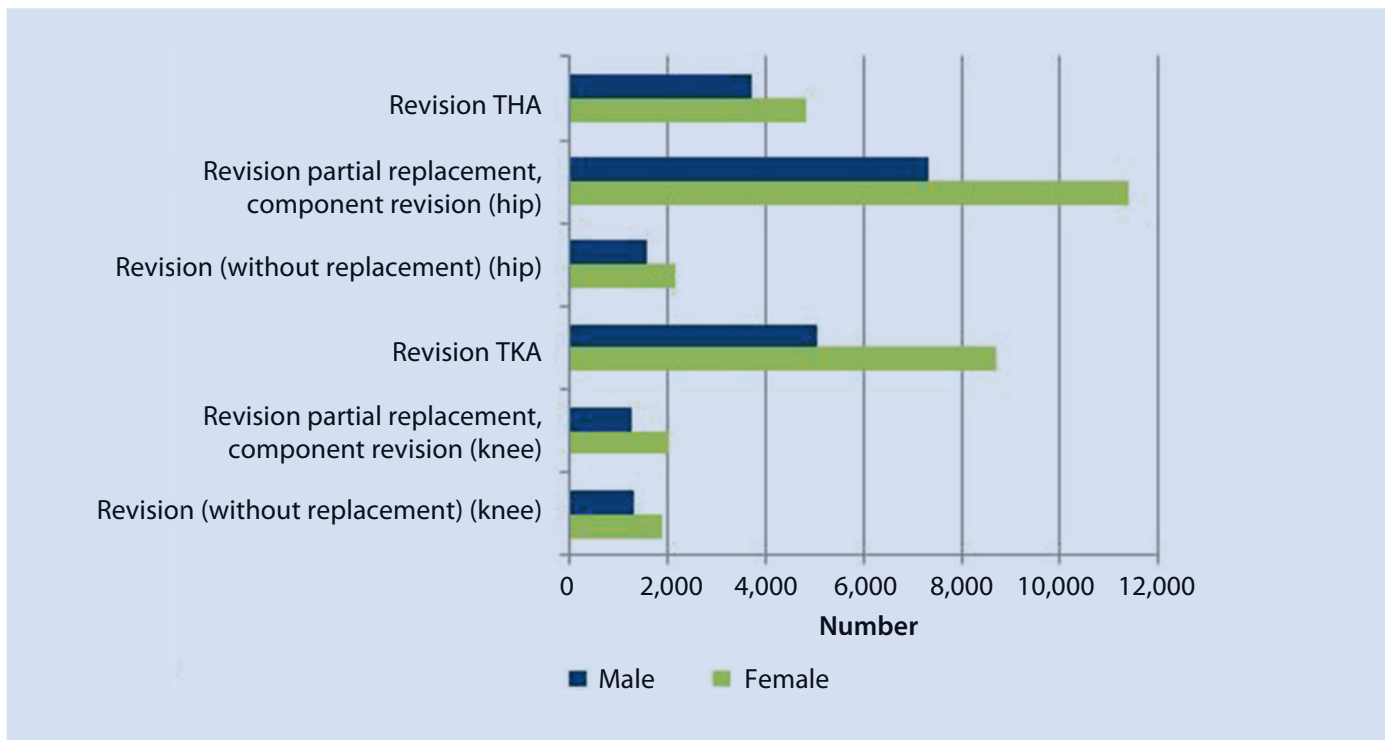

- Fig. 2.5 Utilization (absolute number) of joint replacement procedures on the hip and knee by type of revision replacement (including revisions without replacements) and by sex (2013). (Source: IGES - Federal Statistical Office 2014) 
knee replacements respectively which were conducted in one year (2013). Replacements of acetabular cup components (partial replacement) or of bicondylar surface prostheses were the most common revision replacements performed on the hip and the knee respectively (• Tab. 2.2) (Federal Statistical Office 2014).

In 2013, the highest number of revision total arthroplasties and revisions (partial replacements) were performed in the 75 to 79 year age group. $40 \%$ of all revision total arthroplasties and revisions on the hip and knee were performed in the 70 to 79 year age group. In 2013, the average age of patients who underwent revision total arthroplasty and other revision surgery on the hip was 72.5 years and 69 years for those who underwent revision total arthroplasty and other revision surgery on the knee. These average ages are slightly higher than the average ages of patients who undergo primary surgery (• Fig. 2.4) (Federal Statistical Office 2014).

As with primary arthroplasty, the absolute number of revision total arthroplasties and revisions is higher in women than in men. Considering that the absolute number of primary replacements in men is markedly lower than in women, men undergo comparatively more revisions and revision total replacements (• Fig. 2.5).

However, a direct link between the number of revision total replacements and primary replacements in a certain year cannot be ascertained. The number of revision total replacements should be considered in relation to the cumulative number of primary replacements performed over the past years and decades because endoprostheses have long mean service lives. $\triangleright$ Chapter 6 presents expert opinions on the different aspects of evaluating the prevalence of revision replacements (including revisions without replacements).

\subsection{Regional Distribution}

The regional distribution of hip and knee arthroplasty across the German federal states and districts was evaluated by Schäfer et al. based on accounting data (secondary data) of patients insured with the statutory health insurance AOK. This included 24 million insurees from the years 2005 to 2009. The authors calculated age-standardized surgery rates (primary hip or knee arthroplasty per 100,000 insurees per year). Only total arthroplasties were taken into account. Age-standardized rates (European standard) were calculated in order to minimize distortions arising from demographic differences between the regions and to enable comparisons between regions and other studies (Schäfer et al. 2013).

In 2009, a total of 148 primary hip replacements and 132 primary knee replacements per 100,000 AOK insurees was performed. Marked differences were observed at federal state levels: The lowest rate of hip replacements was documented in Berlin with 120 operations and the highest in Lower Saxony with 168, corresponding to a difference of approximately $40 \%$ (- Fig. 2.6). The rate of knee replacements showed equally distinct regional variations at federal state level (78.4\%): The lowest rate of replacement was again observed in Berlin (90) and the highest number of primary TKAs in the study population was observed in Bavaria (160). Upon solely evaluating federal area states and excluding federal city states, the lowest rates of hip replacements can be observed in Saxony-Anhalt (143) and the lowest rate of knee replacements in Mecklenburg-Western Pomerania (109). The highest are observed in Bavaria, Lower-Saxony and Schleswig-Holstein and Thuringia (Schäfer et al. 2013).

The AOK evaluation also demonstrated major differences at district levels. The lowest hip arthroplasty rate (average value for the period between 2005 and 2009) was 106 cases (in the district Neustadt an der Weinstraße) and the highest rate was 216 cases per 100,000 insurees (in the district Neustadt an der Aisch). The regional differences for TKA were also higher than for hip procedures at district levels (Schäfer et al. 2013).

The German Society for Orthopaedics and Trauma (DGOU) published a report on behalf of the foundation "Bertelsmann Stiftung " describing the regional differences and influencing factors on knee arthroplasty. This report also describes distinct regional differences for knee arthroplasty procedures (- Fig. 2.7). The evaluation was also based on accounting data from AOK insurees but these were obtained from the period between 2005 and 2011. This investigation also found that in 2011, age-standardized utilization of knee replacement 


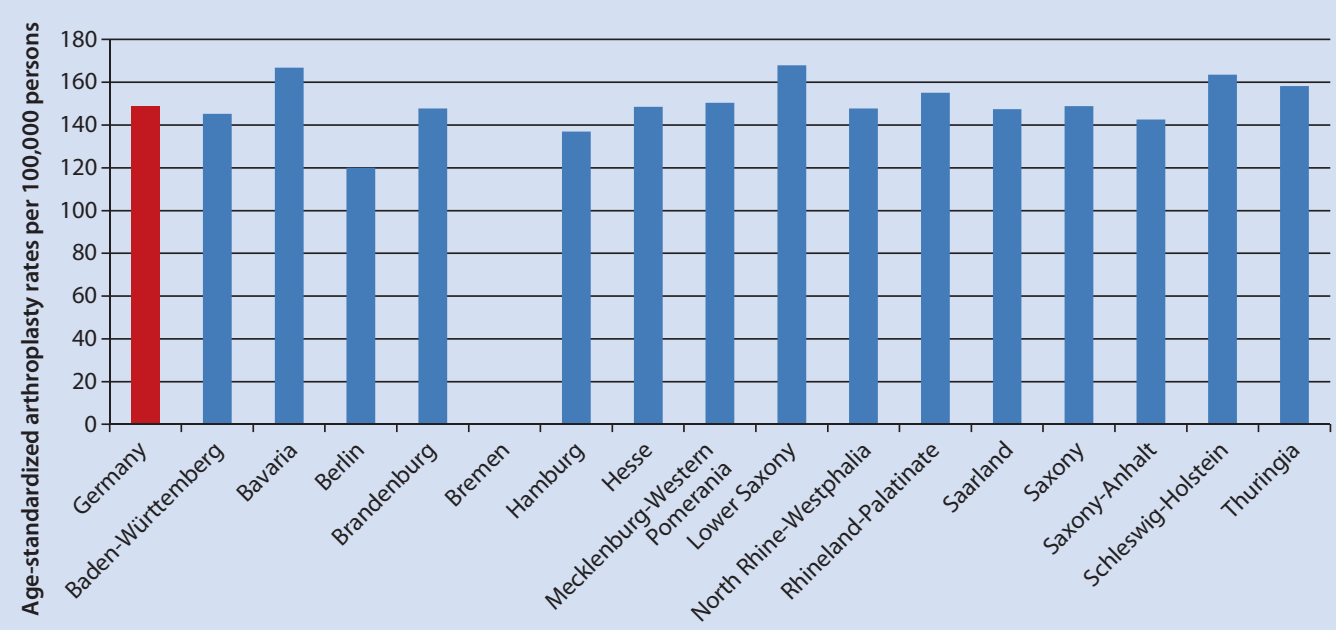

Federal state

- Fig. 2.6 Age-standardized primary hip arthroplasty rates per 100,000 AOK insurees in 2009. (Source: IGES - Schäfer et al. 2013)

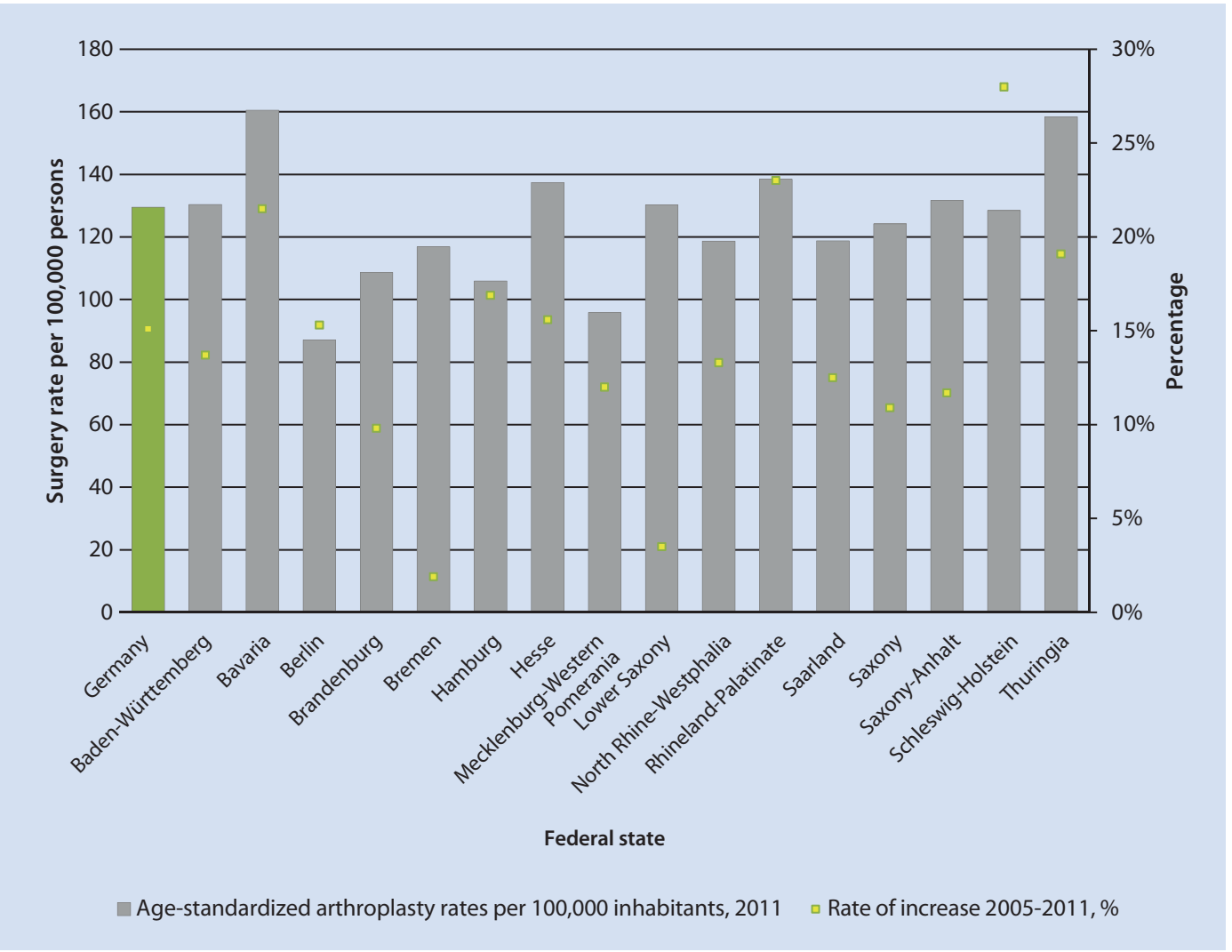

- Fig. 2.7 Age-standardized primary knee arthroplasty rates per 100,000 AOK insurees in 2011, by federal state (patient domicile) and as a national average in Germany, with increases of arthroplasty rates, 2005-2011. (Source: IGES - Lüring et al. 2013) 


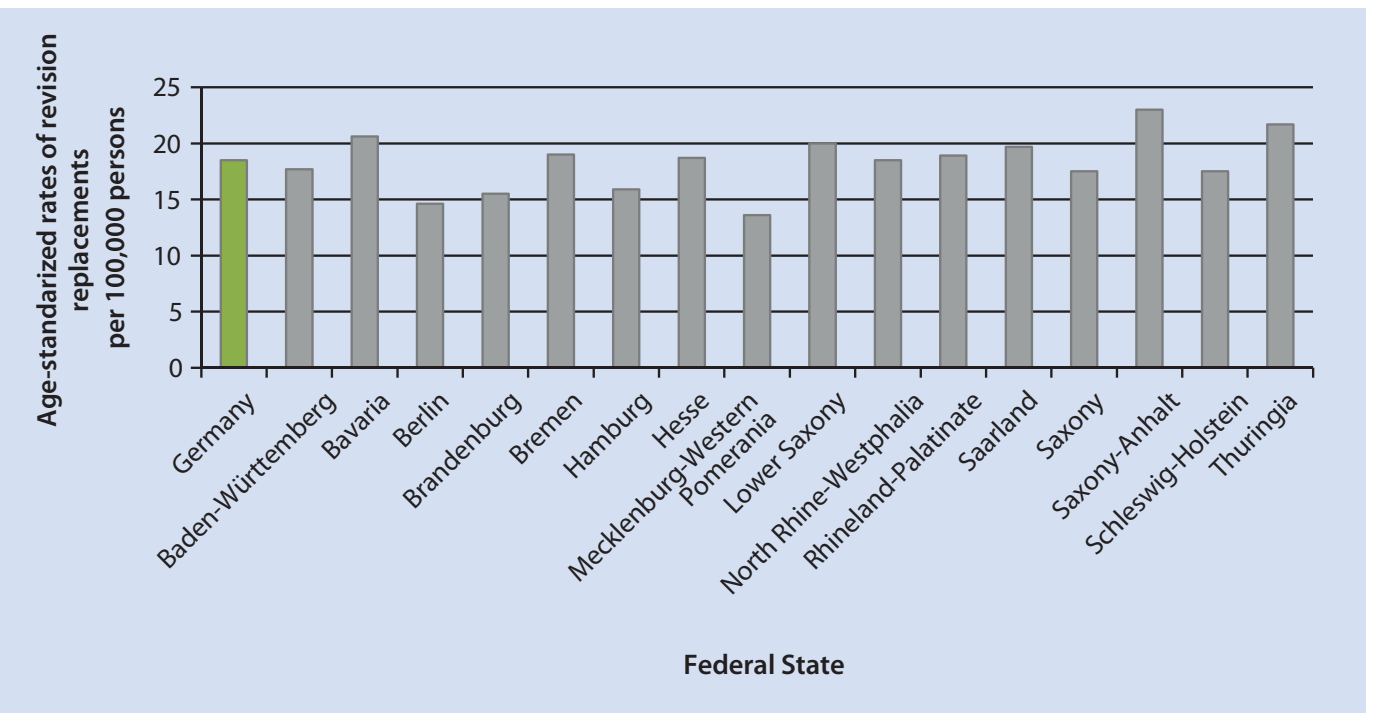

Fig. 2.8 Age-standardized revision knee arthroplasty rates per 100,000 inhabitants, by federal state (patient domicile) and as the national average in Germany (2011). (Source: IGES - Lüring et al. 2013)

procedures was highest in Bavaria and lowest in Berlin. According to the calculations, above-average increases in rates in the years 2005 to 2011 can be observed for patients in the federal states of Schleswig-Holstein, Rhineland-Palatinate, Bavaria, Thuringia, Hamburg, Hesse and Berlin (Lüring et al. 2013).

In the East German regions, the numbers of both types of joint replacement procedures were generally below the average value (except Thuringia) (Schäfer et al. 2013).

The numbers correlated with the osteoarthritis incidence (prevalence) whereby regions with high incidences had comparatively higher rates of THAs and TKAs. Further variables that could explain the regional differences in utilization were local numbers of specialist physicians (orthopedists), regional socioeconomic status and patients living in urban areas. The lower the regional number of orthopedists and the higher the socioeconomic status of the population were in a region, the higher the rate of total arthroplasty procedures amongst insurees living in that region. Total arthroplasties were performed considerably less frequently in urban areas than in rural areas (Schäfer et al. 2013).

- Fig. 2.8 shows Lüring et al.«s calculations for age-standardized surgery rates for revision replace- ments on the knee per 100,000 inhabitants in 2011, according to federal states of patient domiciles and using the national average as a comparison. Revision replacements were defined as "any renewed surgery on the same knee joint $"$.

The analysis shows that in 2011, the highest numbers of revision knee replacements in relation to the number of inhabitants were performed in Saxony-Anhalt, Thuringia, Bavaria and Lower-Saxony. Patients in Mecklenburg-Western Pomerania had the lowest rates of revision.

- Fig. 2.9 clearly demonstrates that surgery rates in the federal states have in part increased considerably over the past ten years. However, the graph differentiates between the rates of increase for the periods between 2005 and 2008 and between 2008 and 2011, illustrating that the rise in surgery rates was considerably higher in the earlier period than in the later period (with the exception of Bremen). From 2008 , the rates of increase generally tend to be lower and even show declines in some federal states (Lüring et al. 2013).

With this, federal states in the southeast had almost consistently higher rates of surgery than in the northeast. At district level, the differences are even more pronounced. With regard to primary replacements, the district with the highest rate of replace- 


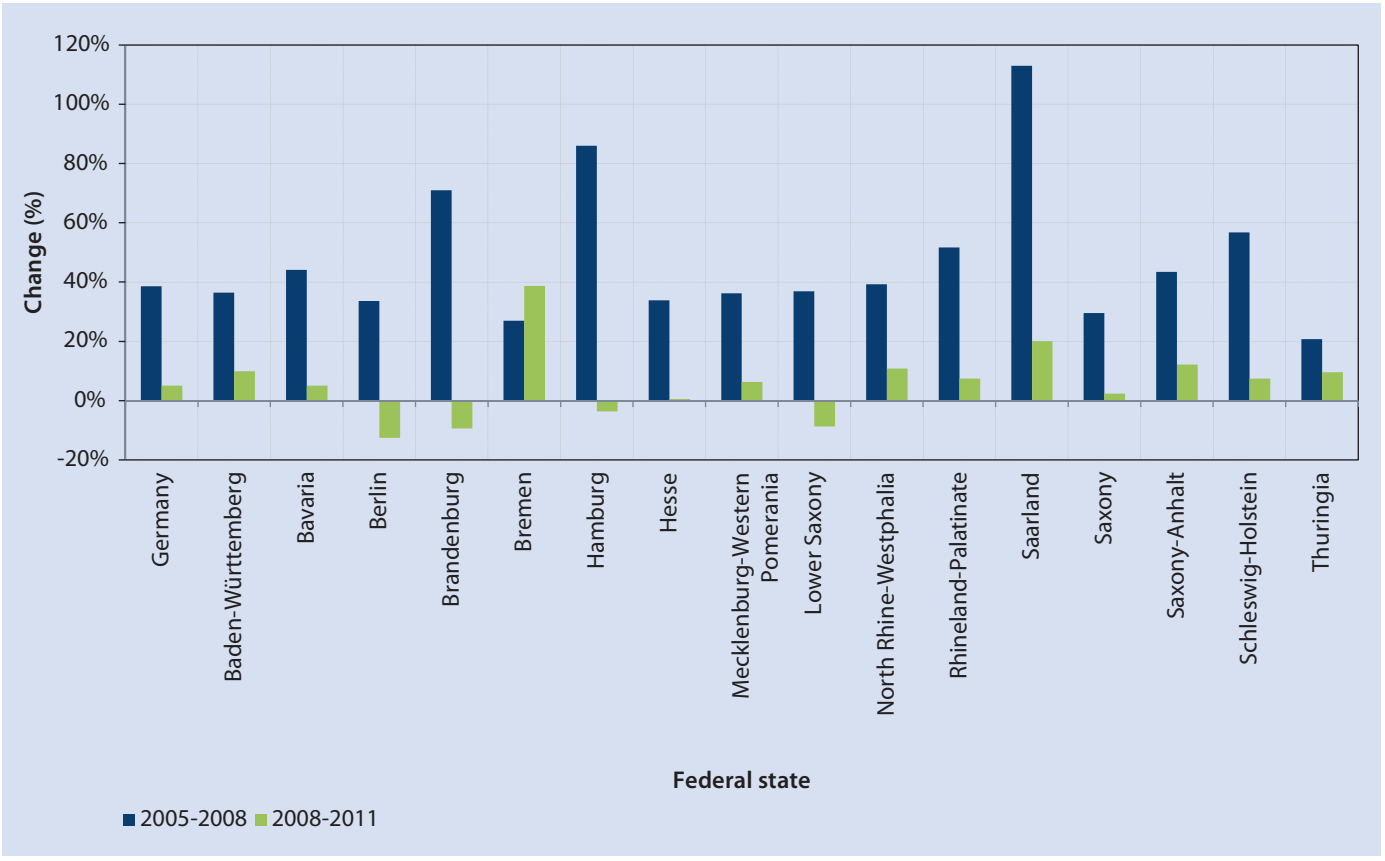

Fig. 2.9 Rates of change in age-standardized revision knee replacement rates, 2005-2008 and 2008-2011. (Source: IGES Lüring et al. 2013)

ments had a 2.9-fold higher rate of knee arthroplasty than the district with the lowest rate. With regard to revisions, the greatest difference between two districts was 4.9-fold (Lüring et al. 2013).

The report discusses manifold reasons for the differences in prevalence. One aspect is that regional differences in access to hospital care exist. Additionally, a bias is created in that patient domiciles and the place of surgery are not in the same region. Additional matters of discussion are revenue structure and that the remuneration system may set wrong incentives and consequently also contribute to the regional differences. The authors, however, emphasize that the observed increasing case numbers which are not caused by demographic changes should not solely be attributed to wrong financial incentives (Lüring et al. 2013). On the whole, however, the data is insufficient for establishing causal relationships (Lüring et al. 2013).

\subsection{Case Number Developments}

\subsubsection{Primary Arthroplasty}

Since 2007, the absolute number of primary hip and knee arthroplasties has been increasing, which is in line with the growing number of older people (risk population) in the population. From 2007 to 2014, the prevalence of primary hip and knee replacements amongst patients over the age of 70 years (as determined on 31 December in the respective year) did not increase and remained stable at $1.1 \%$ for primary hip replacements (2007 and 2014) and between $0.7 \%$ and $0.6 \%$ (2007 and 2014 respectively) for primary knee replacements (• Fig. 2.10) (own calculation, Federal Statistical Office 2014, Federal Statistical Office 2015). After an increase in the absolute number of primary replacements from 2007 to 2011, the number of hip replacements showed a slight decline from 213,935 cases in 2011 to 210,384 cases in 2013 , followed by an increase to 219,325 cases in 2014. In 2009, the number of primary knee replacements was 159,137, which remained almost 


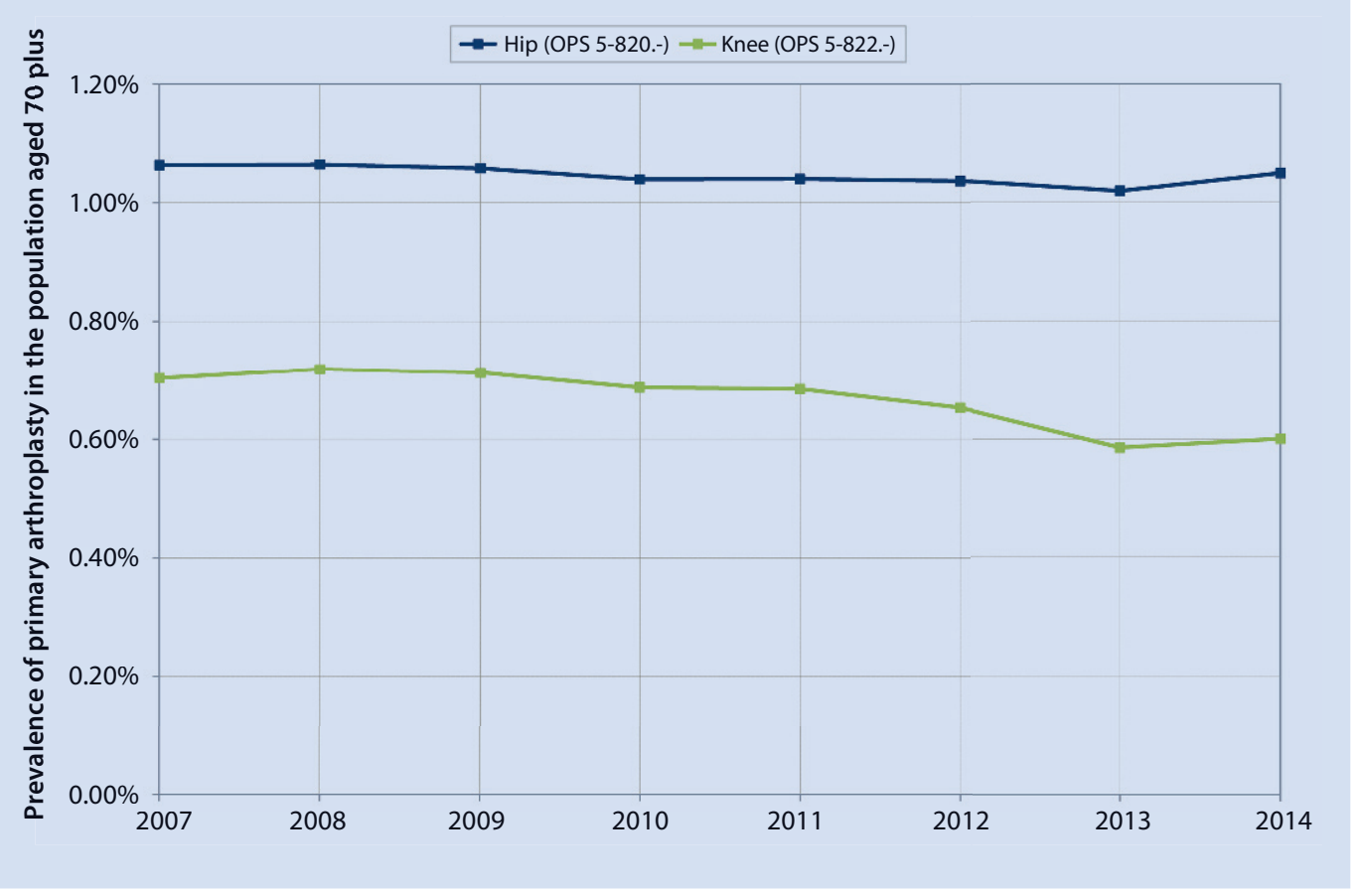

- Fig. 2.10 Prevalence of primary hip and knee replacements in the population aged 70 plus (2007 to 2014). (Source: IGES - own calculation, Federal Statistical Office 2014, Federal Statistical Office 2015)

unchanged in 2010 and 2011 and subsequently declined. In 2013, $7.6 \%$ fewer primary knee replacements were performed than in 2008 and $10.1 \%$ fewer primary replacements (absolute number) than during the peak year 2009.

Changes in case numbers over time can be observed when examining the utilization of THA with regard to the fixation technique selected. During the six-year observational period, the number of uncemented total arthroplasties (not including custommade prostheses) rose by $5 \%$ in absolute numbers. The utilization of cemented procedures decreased in the same period: Cemented and partially cemented total replacements declined by $33 \%$ and $9 \%$ respectively from 2008 to 2013. Custom-made prostheses only played a marginal role (• Fig. 2.11).

Case numbers for the four most common types of primary knee arthroplasty have been declining over the past few years (- Fig. 2.12). The decline in the number of primary arthroplasties is primarily due to a reduced utilization of cemented total replacements.
An evaluation of the case number developments for primary hip and knee replacements in Germany from 2005 to 2011 showed that the increase in the number of primary hip replacements can largely be ascribed to demographic developments. In contrast, non-demographic factors prevailed with regard to the increase in primary knee replacements (Wengler et al. 2014).

If case number developments cannot be sufficiently explained by the demographic developments, this may be an indication of an existing oversupply or shortage of care (Barmer GEK 2010). Besides demographics, other factors and their respective changes (medical, economic, systemic, Section 2.4) influence the prevalence of utilization of medical services over time. Often, these effects cannot be sufficiently quantified ( $\triangleright$ Chapter 6 ). 


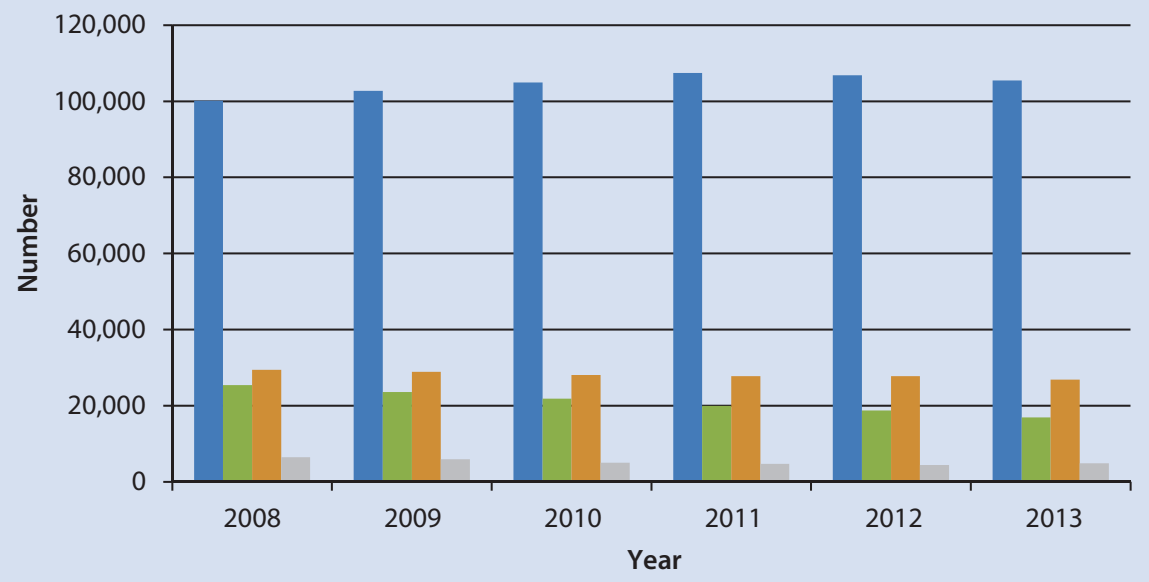
- Total arthroplasty - uncemented
Total arthroplasty - hybrid
- Total arthroplasty - cemented
Custom-made prothesis (uncemented, cemented, hybrid)

- Fig. 2.11 Absolute number of primary THAs performed, by fixation technique, over time (2008 to 2013). (Source: IGES Federal Statistical Office 2014)

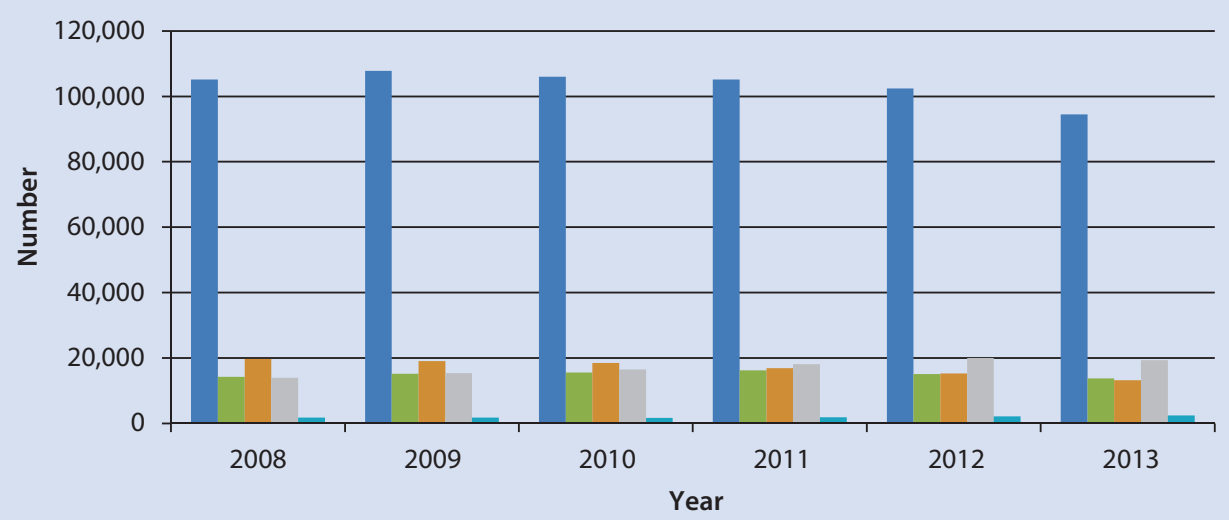

\footnotetext{
- Total replacement - cemented $\quad$ Total replacement - uncemented $\quad$ Total replacement - hybrid Partial replacement - cemented other
}

- Fig. 2.12 Absolute number of primary knee replacements performed, by fixation technique (2008 to 2013). (Source: IGES - Federal Statistical Office 2014) 


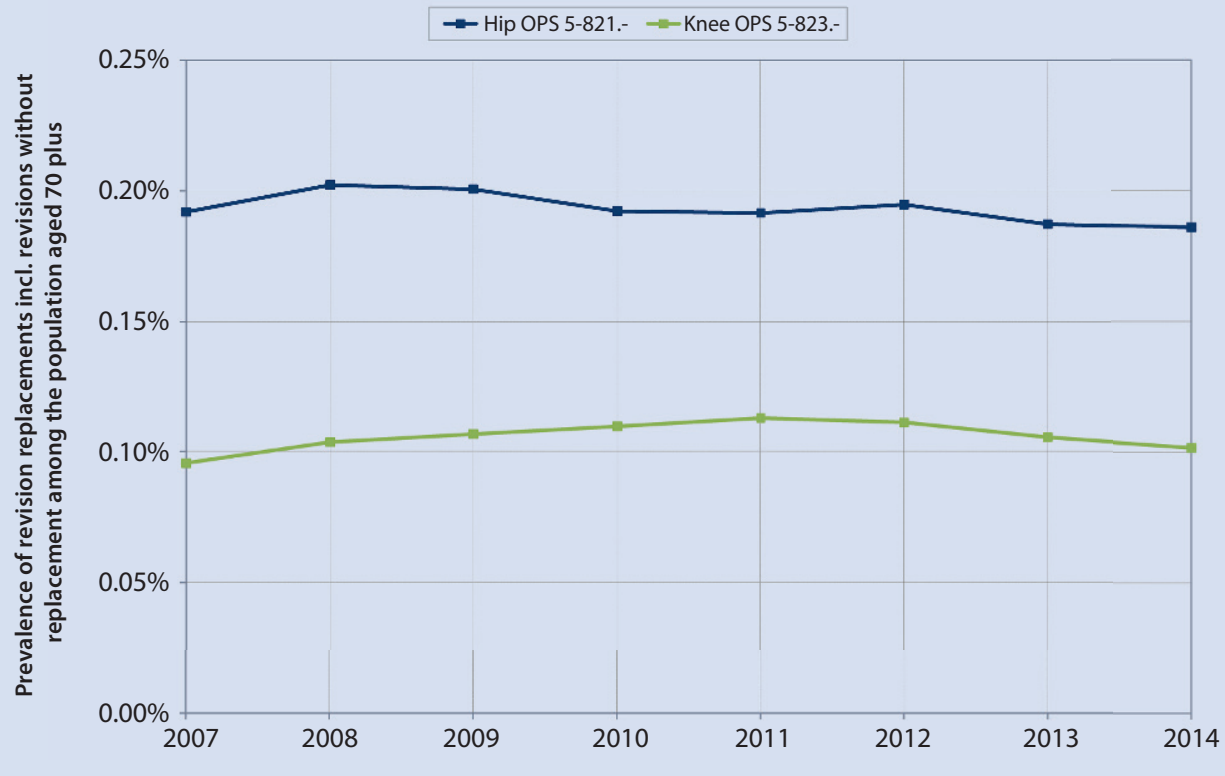

- Fig. 2.13 Prevalence of revision total hip and knee replacements and revisions (without replacements) in the population aged 70 plus over time (2007 to 2014). (Source: IGES - own calculation, Federal Statistical Office 2014, Federal Statistical Office 2015)

\subsubsection{Revision Total Arthroplasty and Revision Surgery}

The absolute number of all revision total arthroplasties and revisions without replacement performed on the hip and knee increased in the period between 2007 and 2014. Since 2007, the prevalence of hip and knee revision replacement surgery (including revisions without replacements) amongst people in the population aged 70 plus (population as determined on 31 December of the respective year) has remained stable at $0.19 \%$ (2007 and 2014) for hip replacement surgery and at $0.10 \%$ for knee replacement surgery (• Fig. 2.13) (own calculation, Federal Statistical Office 2014, Federal Statistical Office 2015). During the observational period from 2008 to 2013 , the absolute number of revision total hip replacements in relation to total replacements decreased by $12.2 \%$. This is predominantly due to a decrease in the number of cemented THAs which declined steadily by altogether $32.8 \%$ from 2008 to 2013. In contrast, the number of DRG-coded revision replacements of uncemented total replace- ments increased by $8.5 \%$ during the same period. This increase can presumably also be ascribed to the higher number of uncemented arthroplasties. Partially cemented total arthroplasties and custom-made prostheses were also revised less frequently in 2013 than in 2008, with a decrease of $24.9 \%$ and $17.0 \%$ respectively. When an uncemented total arthroplasty is revised, it is usually replaced with another uncemented total arthroplasty (33.2\% of uncemented total replacements) or with a custom-made prosthesis (38.7 \%) (• Fig. 2.14).

From 2008 to 2013, the most frequent revision knee replacement performed by far was bicondylar surface replacement, followed by revisions without replacements and unicondylar sledge prosthesis replacements (•Tab. 2.3).

$37.5 \%$ of all the observed bicondylar surface prosthesis replacements are recorded with the synthetic inlay replacements. This procedure is easier to perform and associated with fewer complications than replacements of other implant components with bone fixation (Lüring et al. 2013). Inlay replacement was the most common type of revision 


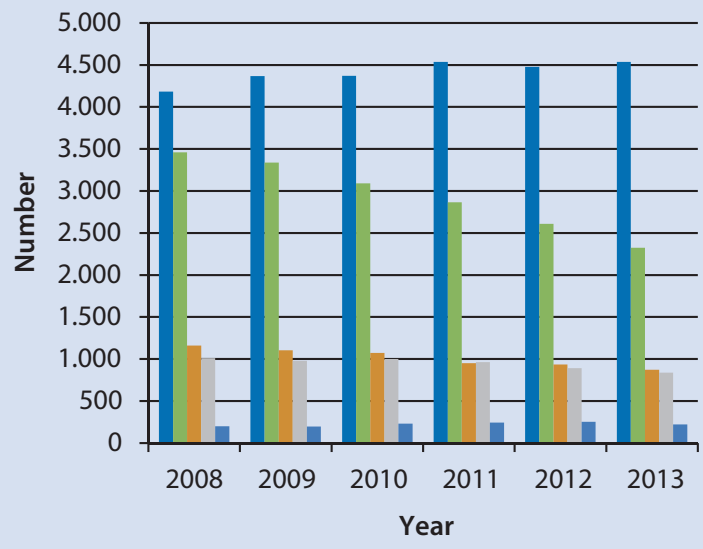

- Total arthroplasty - uncemented

- Total arthroplasty - cemented

Hybrid - partially cemented

Custom-made prosthesis

- Short-stem femoral head prosthesis

- Fig. 2.14 Absolute number of revision hip replacements performed, by fixation technique, over time (2008 to 2013$)$. (Source: IGES - Federal Statistical Office 2014)

- Tab. 2.3 Absolute number of revision replacements and revisions (without replacements) performed on the knee over time (2008 to 2013)

\begin{tabular}{|c|c|c|c|c|c|c|c|}
\hline OPS & name & 2008 & 2009 & 2010 & 2011 & 2012 & 2013 \\
\hline $5-823.0$ & Revision (without replacement) & 3,497 & 3,421 & 3,444 & 3,518 & 3,291 & 3,213 \\
\hline $5-823.1$ & $\begin{array}{l}\text { Unicondylar sledge prosthesis replace- } \\
\text { ment }\end{array}$ & 1,971 & 1,974 & 2,057 & 2,297 & 2,443 & 2,317 \\
\hline $5-823.2$ & $\begin{array}{l}\text { Bicondylar surface prosthesis replace- } \\
\text { ment }\end{array}$ & 10,590 & 11,049 & 11,821 & 11,916 & 11,614 & 11,290 \\
\hline $5-823.3$ & Hinged endoprosthesis replacement & 1,011 & 1,068 & 1,127 & 1,245 & 1,255 & 1,222 \\
\hline $5-823.4$ & Custom-made prosthesis replacement & 480 & 535 & 529 & 585 & 563 & 533 \\
\hline $5-823.5$ & Patella prosthesis replacement & 450 & 446 & 535 & 516 & 528 & 439 \\
\hline 5-823.b & $\begin{array}{l}\text { Replacement of an endoprosthesis with } \\
\text { enhanced flexion }\end{array}$ & 866 & 811 & 824 & 774 & 840 & 699 \\
\hline 5-823.c & $\begin{array}{l}\text { Replacement of an interpositional non- } \\
\text { anchored implant }\end{array}$ & 184 & 178 & 174 & 132 & 119 & 100 \\
\hline 5-823.f & $\begin{array}{l}\text { Replacement of a bicompartmental } \\
\text { prosthesis }\end{array}$ & 0 & 480 & 512 & 461 & 516 & 459 \\
\hline 5-823.h & $\begin{array}{l}\text { Replacement of an endoprosthetic joint } \\
\text { without movement function }\end{array}$ & 0 & 0 & 0 & 63 & 84 & 112 \\
\hline $5-823 . x$ & Other & 242 & 225 & 241 & 202 & 194 & 188 \\
\hline 5-823.y & Unspecified & 31 & 41 & 25 & 19 & 32 & 16 \\
\hline
\end{tabular}

Source: IGES - Federal Statistical Office (2014) 
Tab. 2.4 Absolute number of revision bicondylar surface prosthesis replacements, over time (2008 to 2013)

\begin{tabular}{|c|c|c|c|c|c|c|c|}
\hline OPS & Description & 2008 & 2009 & 2010 & 2011 & 2012 & 2013 \\
\hline $5-823.20$ & Same prosthesis type & 305 & 247 & 255 & 228 & 241 & 247 \\
\hline $5-823.21$ & $\begin{array}{l}\text { With a different surface prosthesis, } \\
\text { uncemented }\end{array}$ & 47 & 53 & 50 & 31 & 32 & 38 \\
\hline $5-823.22$ & $\begin{array}{l}\text { With a different surface prosthesis, } \\
\text { (partially) cemented }\end{array}$ & 1,212 & 1224 & 1210 & 1167 & 1116 & 1101 \\
\hline $5-823.23$ & $\begin{array}{l}\text { With a hinged endoprosthesis, } \\
\text { uncemented }\end{array}$ & 39 & 58 & 56 & 59 & 67 & 68 \\
\hline $5-823.24$ & $\begin{array}{l}\text { With a hinged endoprosthesis, (partially) } \\
\text { cemented }\end{array}$ & 2,093 & 2275 & 2474 & 2557 & 2494 & 2362 \\
\hline $5-823.25$ & $\begin{array}{l}\text { With a custom-made prosthesis, } \\
\text { uncemented }\end{array}$ & 68 & 71 & 87 & 80 & 84 & 91 \\
\hline $5-823.26$ & $\begin{array}{l}\text { With a custom-made prosthesis, } \\
\text { (partially) cemented }\end{array}$ & 1,765 & 1938 & 2126 & 2110 & 1927 & 1763 \\
\hline $5-823.27$ & Inlay replacement & 3,796 & 3961 & 4240 & 4507 & 4539 & 4534 \\
\hline $5-823.28$ & Partial replacement of femoral component & 287 & 255 & 311 & 257 & 284 & 262 \\
\hline $5-823.29$ & Partial replacement of tibial component & 887 & 875 & 934 & 843 & 774 & 738 \\
\hline $5-823 . x$ & Other & 91 & 92 & 78 & 77 & 56 & 86 \\
\hline
\end{tabular}

performed in 2008. By 2013, the number of inlay replacements had increased by $19.4 \%$ whereas other commonly performed types of surgery showed lower rates of increase. In a revision procedure, the entire surface prosthesis is usually removed and replaced with cemented hinged or custom-made prostheses unless solely the inlay is being replaced. Other procedures only play a minor role. Only $3.2 \%$ of all revision total replacements (i.e. not including partial replacement) are performed without using cement (•Tab. 2.4).

Due to the described increase in primary knee replacements up until 2009, Lüring et al. (2013) predicted a corresponding increase in revision knee replacements. According to Federal Statistical Office OPS data, the predicted continuing increase of knee replacements (Haas et al. 2013; Lüring et al. 2013) has not been observed to date (Federal Statistical Office 2014).

Pabinger et al. evaluated the utilization of hip joint replacements in connection with economic data from OECD countries from 1990 to 2011. They found that the rates of increase in surgery are particularly pronounced in the under 65 years age group and therefore expect a strong increase in revision total replacements and revision surgery due to this demographic change (Pabinger and Geissler 2014).

\subsection{International Comparison}

Over the last decades, the absolute number of hip and knee arthroplasties has increased in Germany as well as in other European countries and in the USA (Finkenstädt and Niehaus 2015; Merx et al. 2003; Wengler et al. 2014). The demand for joint replacements has increased with the increasing prevalence of age-related underlying diseases and other risk factors, such as osteoarthritis and osteoporosis, which are associated with a higher risk of femoral neck fractures (• Fig. 2.15, OECD 2014). Reasons for this are related to demographic changes which are accompanied by an increase of people at 


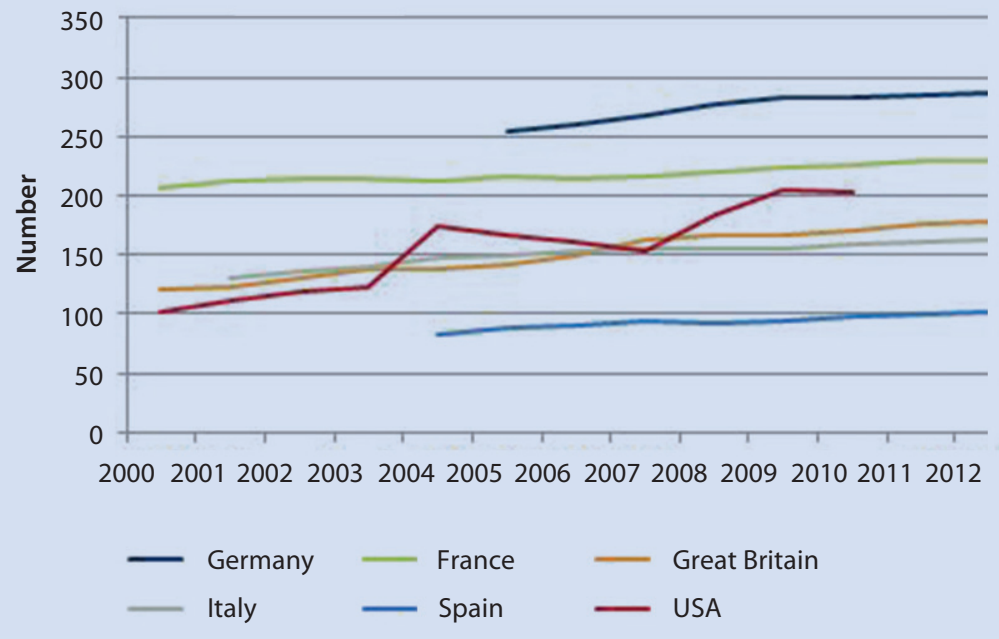

Fig. 2.15 International numbers of hip replacements per 100,000 inhabitants based on OECD data over time (2002 to 2012) (presentation of prevalence rates without age adjustments). (Source: IGES - OECD 2014)

risk for joint replacements, amongst other things (Wengler et al. 2014).

Analyses have demonstrated that after a bias correction of demographic factors, endoprosthetic surgery only increased by $3 \%$ between 2005 and 2011; without this correction it increased by $11 \%$ (Wengler et al. 2014) (Section 2.5.1).

In an international comparison based on OECD data, Germany ranks amongst the top positions for the number of joint replacements performed (• Fig. 2.16 and - Fig. 2.17; OECD 2014). However, the OECD database does not take into account demographic change, current population age structures and other factors influencing the utilization of surgery. As hip and knee replacements are strongly agedependent, statements about country-specific healthcare situations for these procedures derived from this data (oversupply or shortage of care) are not particularly reliable, even solely because country-specific age structures have not been taken into consideration.

Age and age structures differ significantly internationally (• Fig. 2.18). In 2012, around half the German population was 45.53 years or older (median age), making it the country with the second oldest population amongst the OECD countries following Japan. Within Europe, Germany and Italy have the oldest populations (United Nations 2013). A populations « age distribution is relevant with regard to healthcare when the risk of a disease markedly increases with age as this is accompanied by a higher likelihood of requiring certain therapeutic measures such as joint replacements.

A study conducted by the Scientific Institute of the Private Health Insurances (Wissenschaftliches Institut der Privaten Krankenversicherung (WIP)), evaluated the impact of different ages in populations of different countries on the prevalence of 15 different types of surgery including hip and knee arthroplasty. The study was based on data published in the OECD health statistics (Finkenstädt and Niehaus 2015). In the study, Germany, with a median age of 44.3 years, was the country with the oldest population amongst the countries observed, following Japan (44.6) (- Fig. 2.19).

Finkenstädt et al. demonstrated that including age structures of the German population in evaluations has an impact on its international ranking (hip: 32 countries, knee: 21 countries). When age structure is taken into account for hip joint replacements, Germany ranks $2^{\text {nd }}$ instead of $5^{\text {th }}$ following Switzerland, Norway, Austria and Luxemburg. For knee joint replacements, Germany's position shifts from $5^{\text {th }}$ to $8^{\text {th }}$ (• Fig. 2.20 and $\bullet$ Fig. 2.21; Finken- 


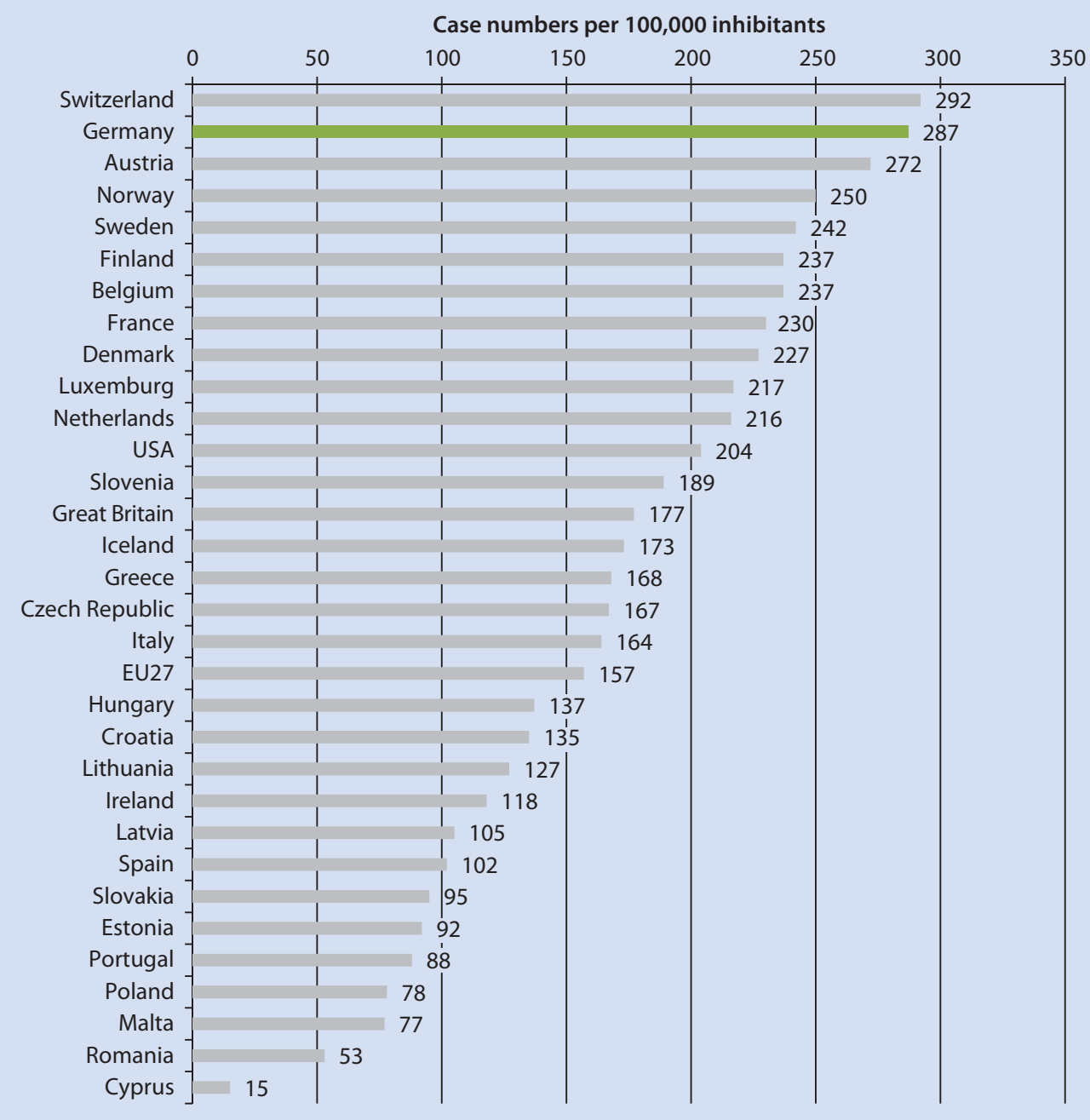

- Fig. 2.16 Numbers of hip joint replacements per 100,000 inhabitants in OECD countries and the USA, 2012 (or latest data) (rates without age adjustments). (Source: IGES - OECD 2014)

städt and Niehaus 2015, 2013). A potential indicator of the status of healthcare that is currently subject to discussion is a factor derived from the lowest and the highest rates of surgery (Niethard et al. 2013). Based on the OECD data, this factor is 2 for hip arthroplasty in Germany (Finkenstädt and Niehaus 2015) and 4 for hip arthroplasty in the USA (Fisher et al. 2010). Knee arthroplasties in Germany differ regionally by a factor of 3.2 (Finkenstädt and Niehaus 2015) and in the USA by a factor of 3.8 (Fisher et al. 2010). For hip operations in particular, a high rate of surgery with a comparatively low level of regional variance permits the assumption that the surgery indications and the standard of care have generally been accepted (Niethard et al. 2015).

Besides demographic factors, social, economic, structural and medical aspects (Merx et al. 2003; Pabinger and Geissler 2014) as well as specific characteristics of the individual national healthcare systems, such as different coding systems and differences in data recording, have an impact on the utilization of medical services and/or how they are 


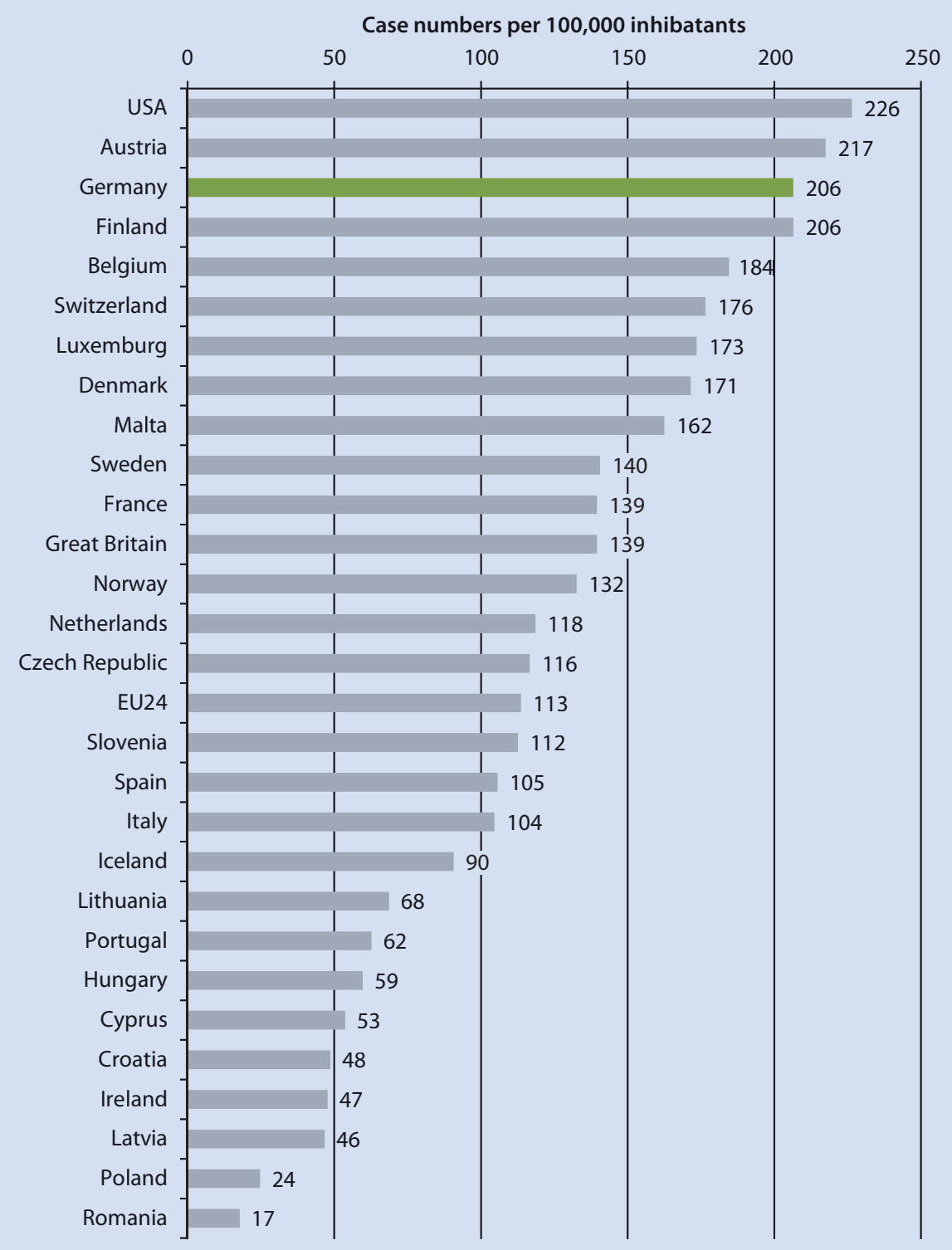

- Fig. 2.17 Numbers of knee joint replacements per 100,000 inhabitants in the OECD countries and the USA, 2012 (or latest data) (presentation of prevalence rates without age adjustment). (Source: IGES - OECD 2014) 


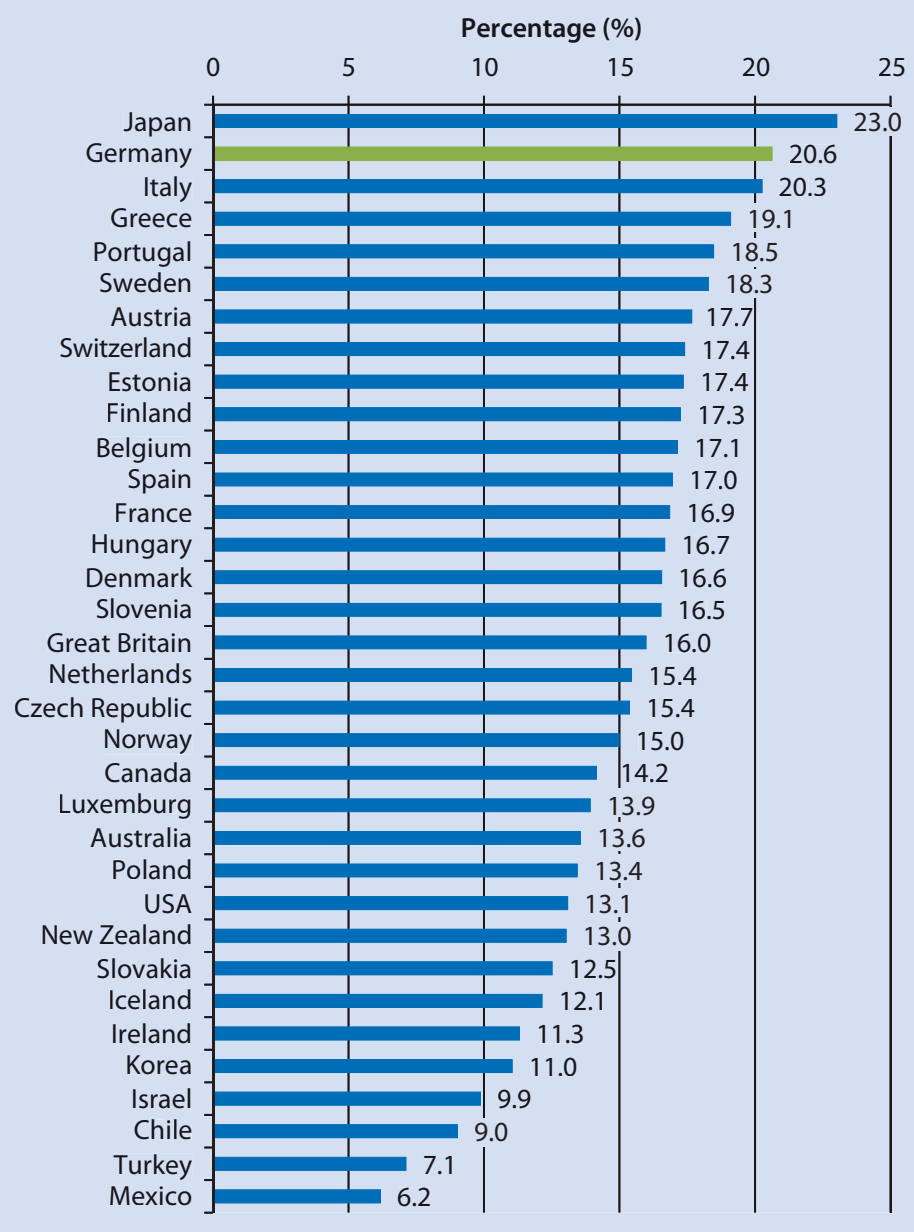

- Fig. 2.18 Percentage of people aged $\geq 65$ years in the total population, 2010. (Source: IGES - OECD 2014)

depicted. Some countries, for example, only report total hip arthroplasty (e.g. Estonia) and others include partial hip replacements (OECD 2014). In some countries, data from private hospitals are not included in the statistics (for example, Ireland) or only partially included (for example, Spain) (Finkenstädt and Niehaus 2015; OECD 2014). The utilization of joint replacement procedures is also related to the economic performance and the per capita healthcare expenditure of a country (Pabinger and Geissler 2014).
This clearly illustrates that data from international comparisons should be interpreted with caution. Evaluations of national healthcare statuses based on international comparisons or OECD data rankings are not reliable without making appropriate adjustments. 


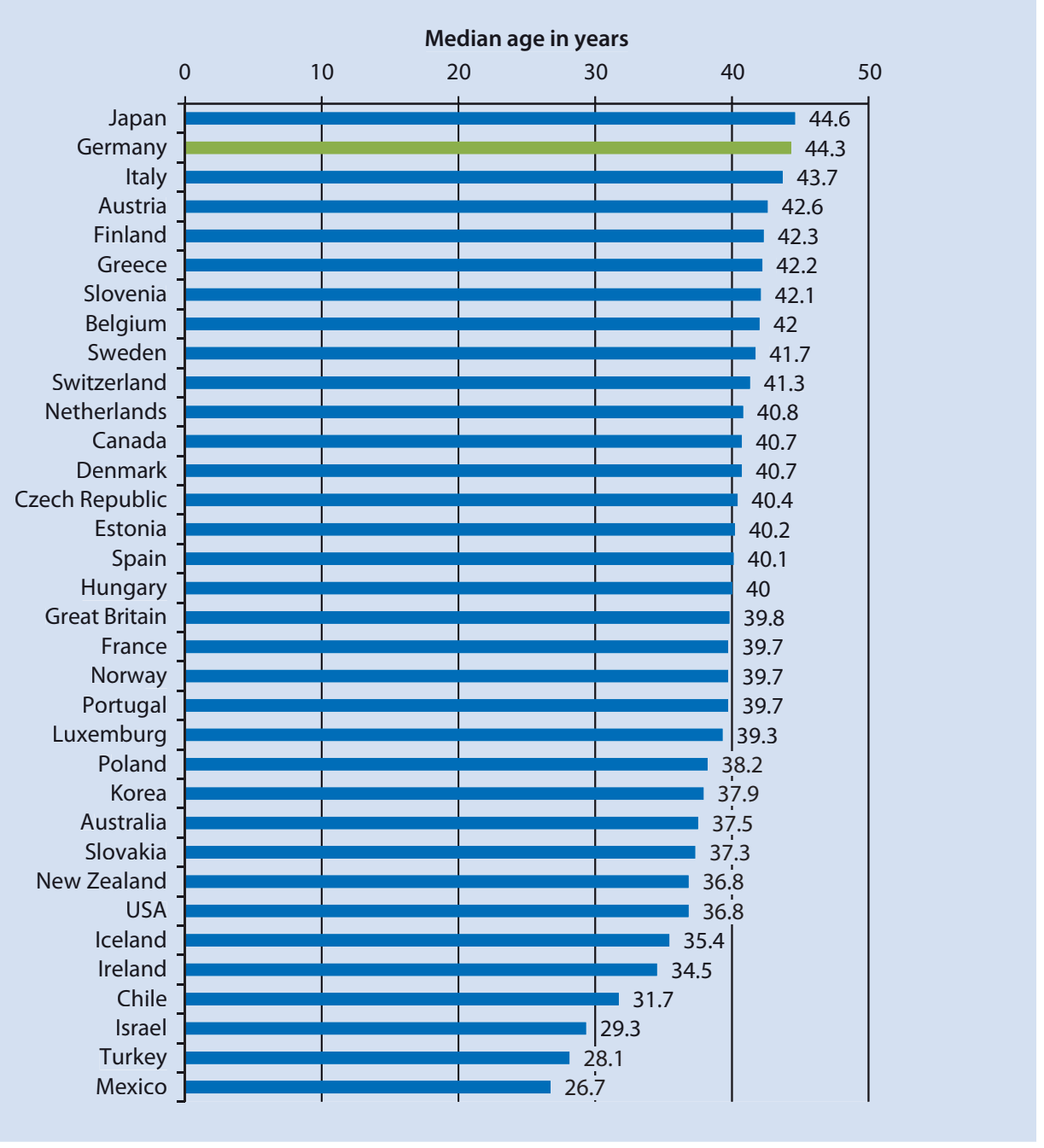

- Fig. 2.19 Median ages in OECD countries, 2010. (Source: IGES - OECD 2014, Finkenstädt and Niehaus 2015) 


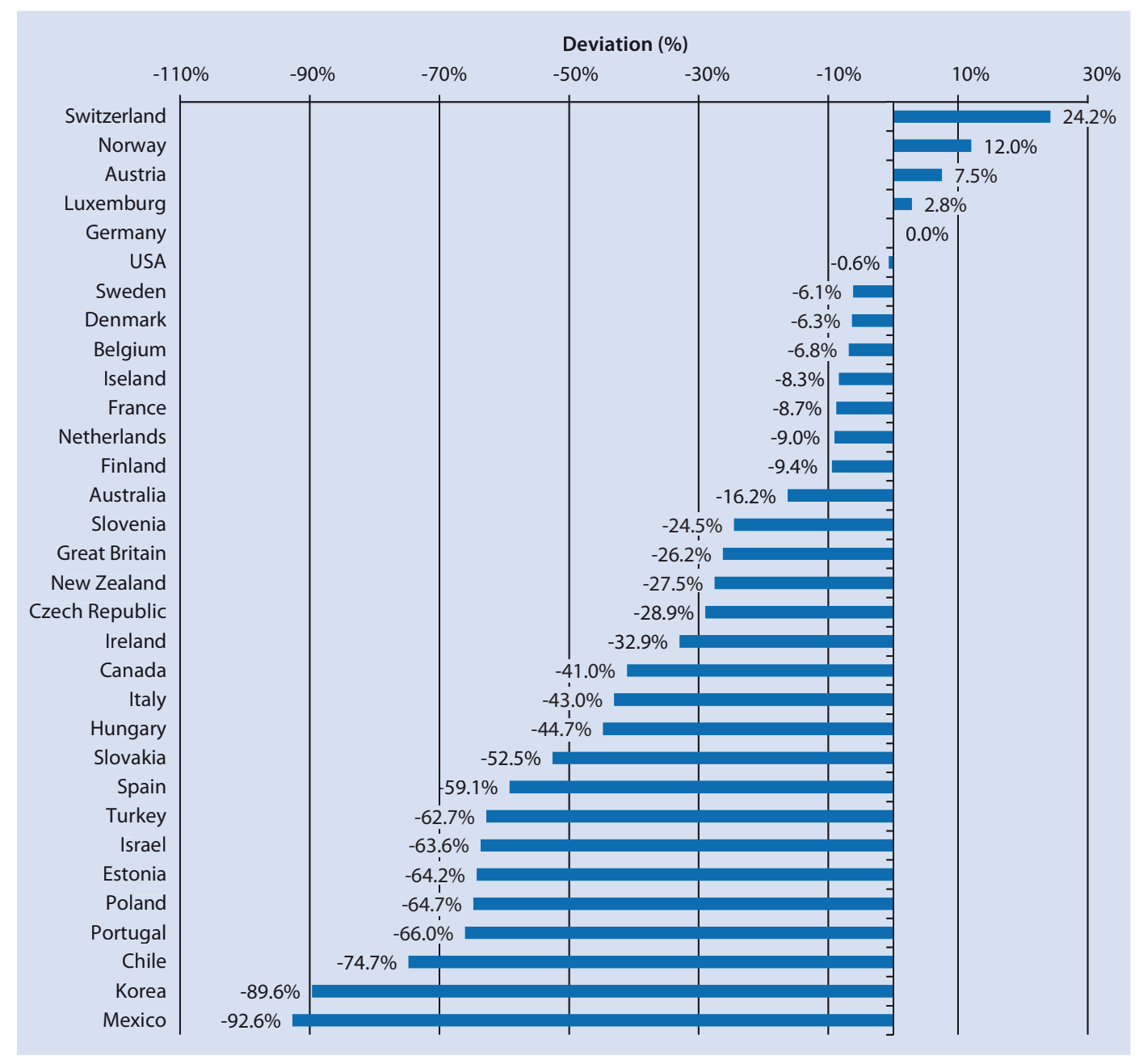

- Fig. 2.20 Case number deviations for hip replacements in Germany following age-standardization. (Source: IGES - OECD 2014, Finkenstädt and Niehaus 2015) 


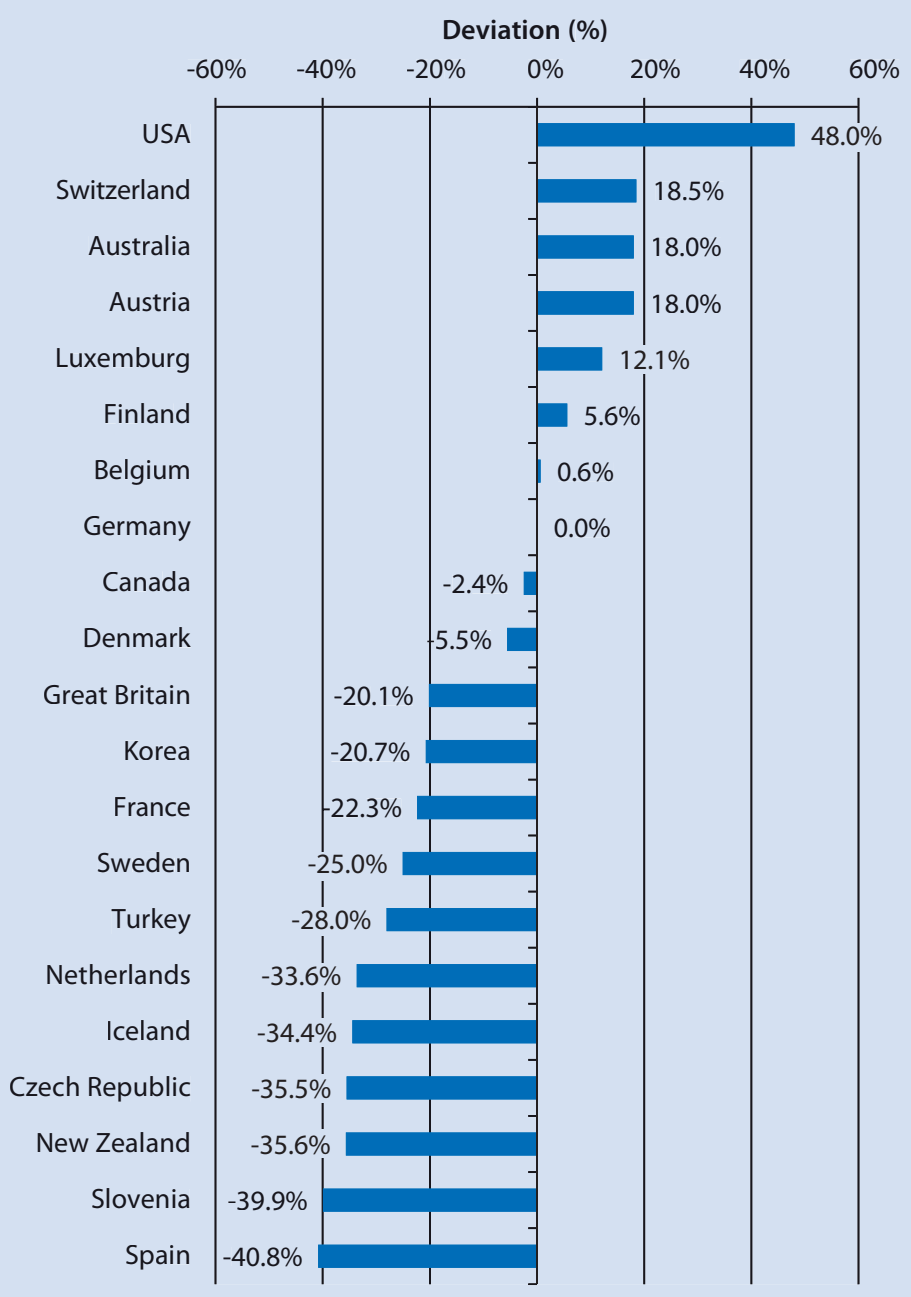

- Fig. 2.21 Case number deviations for knee replacements in Germany following age-standardization. (Source: IGES - OECD 2014, Finkenstädt and Niehaus 2015)

Open Access This chapter is published under the Creative Commons Attribution NonCommercial 4.0 International license (http://creativecommons.org/licenses/by-nc/4.0/deed.de) which grants you the right to use, copy, edit, share and reproduce this chapter in any medium and format, provided that you duly mention the original author(s) and the source, include a link to the Creative Commons license and indicate whether you have made any changes.

The Creative Commons license referred to also applies to any illustrations and other third party material unless the legend or the reference to the source states otherwise. If any such third party material is not licensed under the above-mentioned Creative Commons license, any copying, editing or public reproduction is only permitted with the prior approval of the copyright holder or on the basis of the relevant legal regulations. 


\section{References}

BARMER GEK Report Krankenhaus 2010. Schwerpunktthema: Trends in der Endoprothetik des Hüft- und Kniegelenks. Schriftenreihe zur Gesundheitsanalyse, Band 3. St. Augustin: Asgard-Verlag. ISBN: 978-537-44103-4.

Braun B (2013): Knie- und Hüft-(Total-) Endoprothesen 2008 bis 2012 - hkk Gesundheitsreport. Bremen: hkk Erste Gesundheit. https://www.hkk.de/fileadmin/doc/broschueren_flyer/sonstiges/20131129_hkk_Gesundheitsreport_Knie-Hueft-Tep.pdf. [accessed: 03 November 2015].

DIMDI (2015): Operationen an den Bewegungsorganen (5-78...5-86). OPS Version 2015. Latest update: 17 October 2014. Köln: Deutsches Institut für Medizinische Dokumentation und Information. https://www.dimdi.de/ static/de/klassi/ops/kodesuche/ onlinefassungen/ opshtml2015/block-5-78...5-86.htm [accessed: 23 June 2015].

Finkenstädt V \& Niehaus F (2013): Rationierung und Versorgungsunterschiede in Gesundheitssystemen. Ein internationaler Überblick. Köln: Wissenschaftliches Institut der PKV. ISBN: 978-3-9813569-4-6.

Finkenstädt V \& Niehaus F (2015): Die Aussagekraft von Länderrankings im Gesundheitsbereich. Köln: Wissenschaftliches Institut der PKV. ISBN: 978-3-9813569-7-7.

Fisher E, Bell J, Tomek I, Esty A \& Goodman D (2010): Trends and regional variation in hip, knee, and shoulder replacement. http://www.dartmouthatlas.org/downloads/ reports/Joint_Replacement_0410.pdf [accessed: 06 June 2015].

Haas H, Grifka J, Günther KP, Heller KD, Niethard FU, Windhagen H, Ebner M \& Mittelmeier W (2013): EndoCert. Zertifizierung von Endoprothetischen Versorgungszentren in Deutschland. Stuttgart: Georg Thieme Verlag KG. ISBN: 978-3-13-174081-6.

Lüring C, Niethard FU, Günther KP, Schäfer T, Hannemann F, Pritzkuleit R, Meier W \& Kirschner S (2013): Regionale Unterschiede und deren Einflussfaktoren - Schwerpunkt Knieendoprothetik. Report der Deutschen Gesellschaft für Orthopädie und Orthopädische Chirurgie. Bertelsmann Stiftung.

Merx H, Dreinhofer K, Schrader P, Sturmer T, Puhl W, Gunther KP \& Brenner H (2003): International variation in hip replacement rates. Annals of the rheumatic diseases 62(3), 222-226. ISSN: 0003-4967.

Niethard F, Mahlzahn J, Schäfer T (2013): Endoprothetik und Wirbelsäuleneingriffe - Uneinheitliches Versorgungsgeschehen. Deutsches Ärzteblatt 110(27-28), 1362-1365.

OECD (2014): Health at a Glance: Europe 2014. OECD Publishing. ISBN: 978-92-64-22327-1.

Pabinger C \& Geissler A (2014): Utilization rates of hip arthroplasty in OECD countries. Osteoarthritis Cartilage 22(6), 734-741. DOI: S1063-4584(14)01044-9 pii ;10.1016/j. joca.2014.04.009.
Rabenberg M (2013): Arthrose. Gesundheitsberichterstattung des Bundes. Heft 54. Berlin: Robert Koch-Institut, Statistisches Bundesamt. ISBN: 978-3-89606-219-2.

Schäfer T, Pritzkuleit R, Jeszenszky C, Malzahn J, Maier W, Gunther KP \& Niethard F (2013): Trends and geographical variation of primary hip and knee joint replacement in Germany. Osteoarthritis and Cartilage 21(2), 279-288. DOI: 10.1016/j.joca.2012.11.006.

Statistisches Bundesamt (2014): Gesundheit. Fallpauschalen-bezogene Krankenhausstatistik (DRG-Statistik) Operationen und Prozeduren der vollstationären Patientinnen und Patienten in Krankenhäusern - Ausführliche Darstellung - 2013. Wiesbaden.

Statistisches Bundesamt (2015): https://www.destatis.de/DE/ ZahlenFakten/GesellschaftStaat/Bevoelkerung/Bevoelkerung.html [accessed: 31 May 2015].

United Nations (2013): World Population Prospects: The 2012 Revision, Highlights and Advance Tables. Working Paper No. ESA/P/WP.228. 2015/12/29/. United Nations, Department of Economic and Social Affairs, Population Division. http://esa.un.org/unpd/wpp/Publications/Files/ WPP2012_HIGHLIGHTS.pdf [accessed: 04 November 2015].

Wengler A, Nimptsch U \& Mansky T (2014): Hip and knee replacement in Germany and the USA: analysis of individual inpatient data from German and US hospitals for the years 2005 to 2011. Deutsches Arzteblatt international 111(23-24), 407-416. DOI: 10.3238/arztebl.2014.0407. 